\author{
UNIVERSIDADE DE SÃO PAULO \\ ESCOLA DE ENGENHARIA DE LORENA
}

GUILHERME SILVEIRA SIMÕES

\begin{abstract}
AVALIAÇÃO DE CONDIÇÕES FERMENTATIVAS INICIAIS DE Spathaspora arborariae UFMG HM19.1 NA PRODUÇÃO DE ETANOL A PARTIR DO HIDROLISADO DE BAGAÇO DE CANADE-AÇÚCAR
\end{abstract}


GUILHERME SILVEIRA SIMÕES

\title{
AVALIAÇÃO DE CONDIÇÕES FERMENTATIVAS INICIAIS DE Spathaspora arborariae UFMG-HM19.1 NA PRODUÇÃO DE ETANOL A PARTIR DO HIDROLISADO DE BAGAÇO DE CANA- DE-AÇÚCAR
}

\begin{abstract}
Dissertação apresentada à Escola de Engenharia de Lorena da Universidade de São Paulo para a obtenção do título de Mestre em Ciências do Programa de PósGraduação em Biotecnologia Industrial na área de Microbiologia Aplicada

Orientador: Prof. Dr. Silvio Silvério da Silva
\end{abstract}

Lorena - SP

Julho, 2011 
AUTORIZO A REPRODUÇÃO E DIVULGAÇÃO TOTAL OU PARCIAL DESTE TRABALHO, POR QUALQUER MEIO CONVENCIONAL OU ELETRÔNICO, PARA FINS DE ESTUDO E PESQUISA, DESDE QUE CITADA A FONTE.

\section{Catalogação na Publicação}

Biblioteca "Cel. Luiz Sylvio Teixeira Leite"

Escola de Engenharia de Lorena da Universidade de São Paulo

Simões, Guilherme Silveira

Avaliação de condições fermentativas iniciais de Spathaspora arborariae UFMG-HM19.1 na produção de etanol a partir do hidrolisado de bagaço de cana-de-açucar. / Guilherme Silveira Simões. - 2011.

72 p. : il.

Dissertação (Mestre em Ciências - Programa de Pós-Graduação em Biotecnologia Industrial na Área de Microbiologia Aplicada) - Escola de Engenharia de Lorena da Universidade de São Paulo. 2011.

Orientador: Silvio Silvério da Silva

1. Bagaço de cana-de-açucar 2. Etanol 3. Materiais lignocelulosicos 4. Fermentação 5. Spathaspora arborariae. I. Título

$664.113-\mathrm{CDU}$ 


\section{AGRADECIMENTOS}

Ao Prof. Silvio Silvério da Silva, por diversas razões, dentre elas o profissionalismo, a compaixão, a calma e, principalmente, pelas oportunidades. Uma delas, esse mestrado.

Aos colegas de laboratório, funcionários e professores da EEL-USP pelo aprendizado e oportunidade, se listasse a todos e suas participações precisaria quantidade de páginas maior do que a desse texto. Particularmente, agradeço a Felipe Antunes e a Ellen Giese pelo auxílio na etapa final de escrita

A Thais Milessi pelo auxílio com o hidrolisado e a sempre presente boa vontade em ajudar-me quando pedido e a Karen Alves pelo intenso auxílio durante os experimentos.

Ao Prof.Dr. Messias pelo auxílio nas estatísticas e por ensinar-me tão bem como utilizar essa ferramenta maravilhosa.

A Raquel Cadete, por todos os ótimos conselhos sobre o organismo utilizado e as conversas muito construtivas em suas estadias em Lorena.

A minha familia, Roberto, Noely e Gabriel, pelo suporte incondicional nessa etapa da minha vida, meus três grandes pilares que fizeram-me ver a Beleza nas formas triviais, dar-me a Força para seguir em frente e, principalmente, a Sabedoria para refletir sobre minhas falhas e sucessos.

Aos meus amigos e "irmãos" de Taubaté pela compreensão das noites perdidas e do mal humor constante.

A Wagner Luiz da Costa Freitas e sua família, por nunca fechas as portas de sua casa quando precisei, muito menos por nunca cruzar os braços quando viu-me atrapalhado e, principalmente, por ajudar-me até quando sequer pedi.

A Dr. Ana Paula Leite, por motivar-me e ajudar-me a seguir em frente diante das barreiras que, muitas vezes, eu mesmo colocava a minha frente. Se o arquétipo da Fênix pudesse ser exemplificado, eu utilizaria esse trabalho e sua trajetória 



\section{RESUMO}

SIMÕES, G. S. Avaliação de condições fermentativas iniciais de Spathaspora arborariae UFMG-HM19.1 na produção de etanol a partir do hidrolisado de bagaço de cana-de-açúcar 2011. 72p. Dissertação (Mestrado em Ciências) Escola de Engenharia de Lorena, Universidade de São Paulo, 2011.

O presente trabalho teve como objetivo contribuir para o desenvolvimento de uma tecnologia de obtenção de etanol por via biotecnológica, verificando o comportamento da levedura Spathaspora arborariae UFMG-HM19.1 na fermentação de xilose em hidrolisado hemicelulósico de bagaço de cana-deaçúcar para etanol. Foram elaborados três planejamentos fatoriais $2^{3}$ completos com objetivo de determinar condições favoráveis de suplementação nutricional e fermentação do hidrolisado hemicelulósico de bagaço de cana-de-açúcar. O primeiro experimento teve o intuito de a avaliar o efeito da aeração durante a fermentação de etanol, sendo que as melhores condições para aeração foram a agitação em 200 rpm, volume de hidrolisado $25 \mathrm{ml}$ em frascos de $125 \mathrm{ml}$. Após obtenção desses dados, foram utilizados sulfato de amônio, sulfato de magnésio e extrato de levedura como fatores em um segundo delineamento experimental, onde obteve-se como melhor combinação a utilização de extrato de levedura na concentração de $1 \mathrm{~g} \cdot \mathrm{I}^{-1}$. Finalmente, realizou-se o ultimo planejamento experimental, utilizando os dados experimentais anteriores, utilizando como fatores $\mathrm{o} \mathrm{pH}$, a temperatura e a concentração inicial de inóculo, chegando ao resultados das condições ideais de $\mathrm{pH}(\mathrm{pH}=4)$, temperatura $\left(40^{\circ}\right)$ e concentração inicial de inóculo $\left(0,5 \mathrm{~g} \cdot \mathrm{I}^{-1}\right)$. Apesar das condições indicadas e do satisfatório fator de rendimento de etanol $\left(\mathrm{Y}_{\mathrm{p} / \mathrm{s}}=0,50\right)$, a levedura cultivada nessas condições mostrou-se com uma baixa produtividade $(Q p=0,15)$, assim como suas vantagens, tais como a fermentação em temperatura elevada e baixo $\mathrm{pH}$, assim como um fator de rendimento adequado e uma razoável assimilação de açúcares.

Palavras chave: Etanol, Materiais lignocelulósicos, Fermentação, Spathaspora arborariae, Suplementação, Cana-de-açucar 


\section{ABSTRACT}

SIMÕES, G. S. Evaluation of inital fermentative conditions on Spathaspora arborariae UFMG-HM19.1 in ethanol production using hydrolysate of sugarcane bagasse 2011. 72p. Dissertation (Master of Science) - Escola de Engenharia de Lorena, Universidade de São Paulo, 2011.

The aim of this study is to contribute to the technological development of ethanol production by biotechnological pathways, studying the behavior of the yeast Spathaspora arborariae UFMG-HM19 in the fermentation of xylose in hemicellulosic hydrolyzate of sugarcane bagasse for ethanol. Three experimental designs were made to determine the satisfatory set of factors to produce ethanol from the lignocellulosic material. The first experiment was designed to evaluate the effect of aeration during fermentation to ethanol, that would be better under this conditions: agitation at $200 \mathrm{rpm}, 25 \mathrm{ml}$ volume of hydrolyzed in $125 \mathrm{ml}$ bottles. After obtaining these data, we used ammonium sulphate, magnesium sulphate and yeast extract as factors in a second experiment, which was obtained as the best combination to use yeast extract in a concentration of $1 \mathrm{g.l}^{-1}$. Finally, there was the last experimental design, using previous experimental data, using factors such as $\mathrm{pH}$, temperature and initial concentration of inoculum, even to the results of the ideal conditions of $\mathrm{pH}(\mathrm{pH}=4)$, temperature $\left(40^{\circ} \mathrm{C}\right)$ and initial concentration of inoculums $\left(0,5 \mathrm{~g} \cdot \mathrm{L}^{-1}\right)$. Despite the good conditions indicated and ethanol yield factor $\left(Y_{p / s}=0,50\right)$, the yeast grown under these conditions was shown with a low

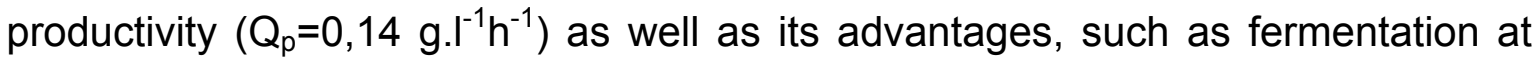
high temperature and low $\mathrm{pH}$, as well as a adequate efficiency and a reasonable sugar assimilation.

Keywords: Ethanol, Lignocellulosic material, Fermentation, Spathaspora arborariae, Supplementation, Sugarcane 


\section{Sumário}

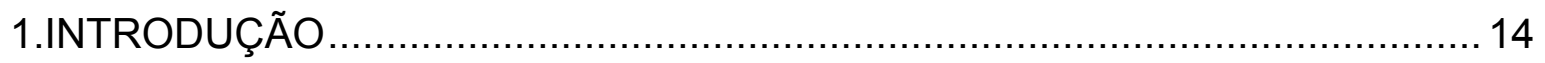

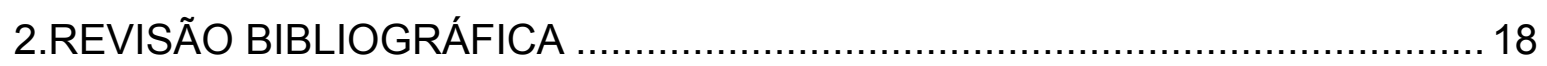

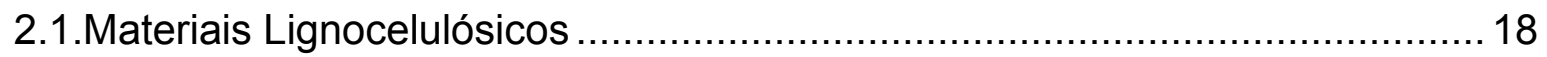

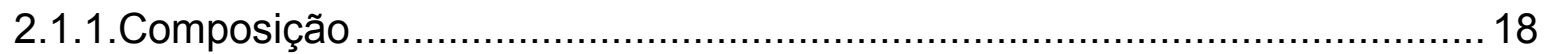

2.1.2.Processos de Pré-tratamento e Hidrólise ....................................... 20

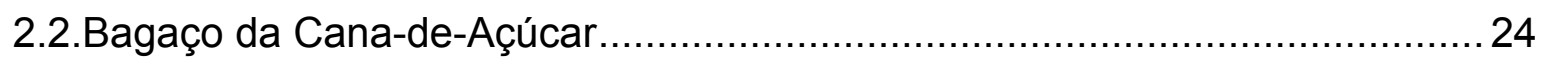

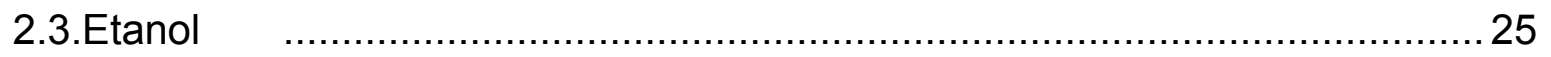

2.3.1.Propriedades e Aplicações ..................................................... 25

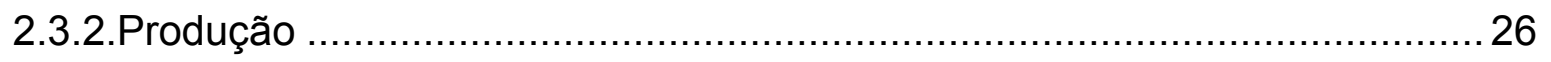

2.4.Principais Parâmetros na Fermentação de Etanol................................ 30

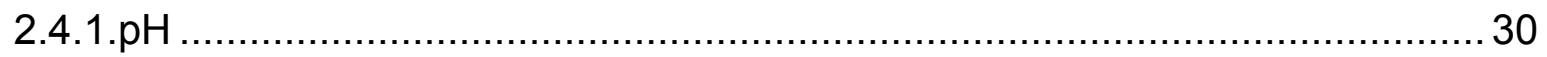

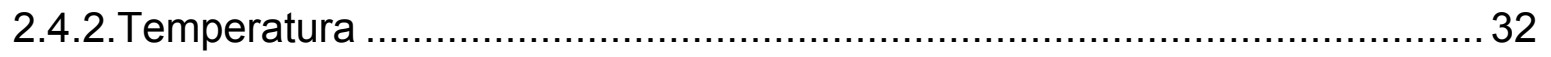

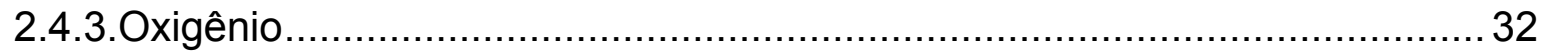

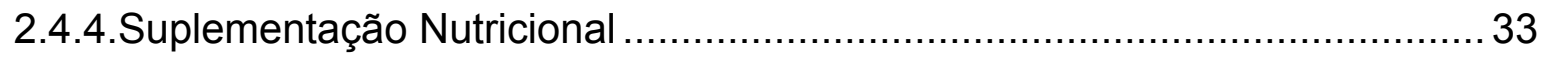

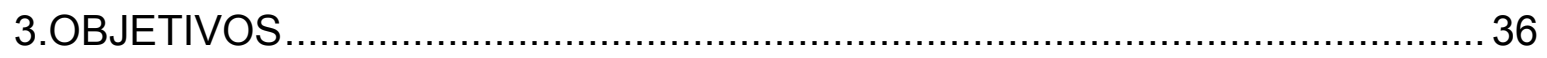

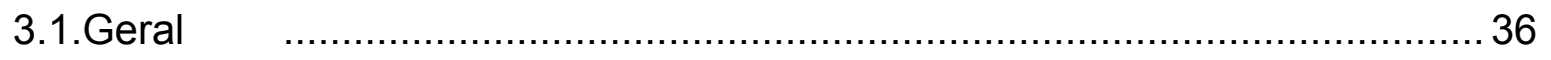

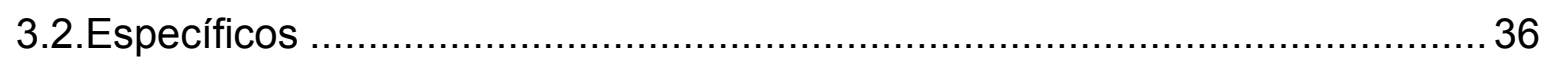

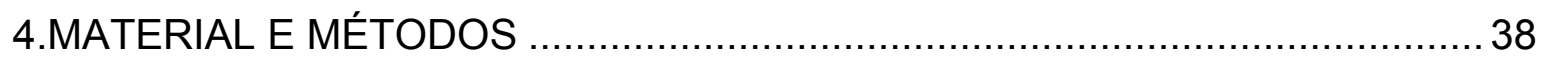

4.1.Obtenção e Preparo do Hidrolisado Hemicelulósico do Bagaço de Cana- de -

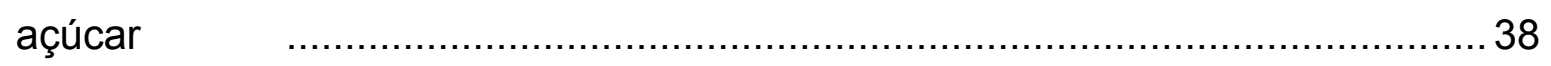

4.2. Concentração e Tratamento do Hidrolisado Hemicelulósico ....................... 38

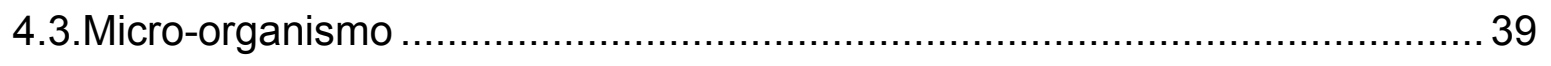

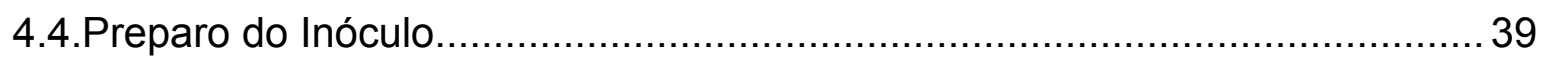

4.5.Avaliação das Condições de aeração ............................................... 39

4.6.Avaliação da Suplementação do Meio de Cultivo .................................... 41

4.7.Avaliação dos Parâmetros da Fermentação ......................................... 42

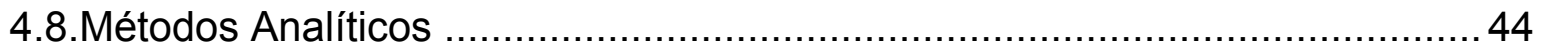


4.8.1Determinação da concentração de açúcares, ácido acético, glicerol e etanol ..

4.8.2.Determinação da concentração de furfural e hidroximetilfurfural .45

4.8.3.Determinação da concentração celular 45

4.8.4.Cálculo dos Parâmetros Fermentativos

5RESULTADOS E DISCUSSÃO

5.1.Hidrolise 48

5.2.Fermentação . 49

5.2.1. Condições de aeração 49

5.2.2.Suplementação nutricional 51

5.2.3.Parâmetros fermentativos 55

6.CONCLUSÕES 62

REFERÊNCIAS 63 


\section{LISTA DE FIGURAS}

Figura 2-1Pré-tratamento da estrutura lignocelulósica do bagaço de cana-deaçúcar (Baseado em: USA, Departament of Energy, 2009). 21

Figura 2-2 Metabolismo de xilose por leveduras (esquema simplificado) Baseado em Parajó et al (1998a) 28

Figura 2-3 Células e ascos de Spathaspora arborariae em Agar V8 diluído após 3 dias a $20^{\circ} \mathrm{C}$. Barra de escala $=5$ um (retirado de CADETE, 2009) 30 Figura 5-1 Diagrama de Pareto com os nutrientes utilizados nos experimentos de aeração 51

Figura 5-2 Diagrama de Pareto com os nutrientes utilizados nos experimentos de suplementação 55

Figura 5-3 Diagrama de Pareto das parâmetros fermentativos experimentais e suas interações. 60 



\section{LISTA DE TABELAS}

Tabela 2-1. Composição de alguns materiais lignocelulósicos ( ${ }^{*} \mathrm{NA}$ - não avaliados) (adaptado de SANCHES, 2009)................................................ 19 Tabela 4-1Fatores e níveis avaliados no planejamento fatorial completo Codificação dos níveis para variáveis avaliadas

Tabela 4-2 Planejamento fatorial do tipo $2^{3}$, com 3 repetições no ponto central, para a avaliação do efeito da na produção de etanol a partir de hidrolisado de cana-de-açúcar pela levedura Spathaspora arborariae 41

Tabela 4-3 Fatores e níveis avaliados no planejamento fatorial completo Codificação dos níveis para variáveis avaliadas

Tabela 4-4 Planejamento fatorial do tipo $2^{2}$, com 3 repetições no ponto central, para a avaliação do efeito da suplementação do hidrolisado com nutrientes, na produção de etanol pela levedura Spathaspora arborariae 42 Tabela 4-5 Níveis dos fatores utilizados no planejamento fatorial fracionário $2^{3}$ três repetições do ponto central. 43

Tabela 4-6 Esquema da matriz de planejamento fatorial fracionário $2^{3}$ com três repetições do ponto central

Tabela 5-1 Caracterização do hidrolisado hemicelulósico do bagaço de cana-deaçúcar bruto e tratado.

Tabela 5-2 Avaliação da aeração na fermentação de xilose e glicose para etanol utilizando a levedura Spathaspora arborariae UFMG-HM19.1 ........................ 50 Tabela 5-3 Análise de Variância para Etanol dos parâmetros utilizados no experimento de aeração 50

Tabela 5-4 Avaliação da suplementação nutricional na fermentação de xilose e glicose para etanol utilizando a levedura Spathaspora arborariae UFMG-HM19.1.

Tabela 5-5 Análise de Variância para Etanol dos parâmetros utilizados no experimento de aeração 54

Tabela 5-6 Avaliação dos parâmetros fermentativos na conversão de xilose e glicose para etanol utilizando a levedura Spathaspora arborariae UFMG-HM19.1 
Tabela 5-7 Análise de Variância para Etanol dos parâmetros utilizados no experimento dos parâmetros fermentativos .....................................................59 


\section{INTRODUÇÃO}

Um dos maiores desafios para a sociedade no século XXI é a demanda crescente de energia, transporte, aquecimento e processos industriais, de modo sustentável.

A preocupação aumenta com o impacto negativo da utilização de combustíveis fósseis no ambiente, como a emissão de gases provocando o efeito estufa, um dos responsáveis pelas alterações climáticas nos dias atuais. Com isso, a sociedade precisa de um cuidado com o meio ambiente, exigindo políticas e produtos ambientalmente limpos, pressionando o governo e a indústria a buscar alternativas.

Tais alternativas criaram novos mercados, como o de créditos de carbono, que tornou-se a saída encontrada por países industrialmente desenvolvidos para manter suas atividades e produções sem grandes mudanças, negociando com nações menos desenvolvidas, cotas de carbono lançados na atmosfera pela intensa atividade industrial.

A negociação de créditos de carbono já beneficia uma série de empresas no Brasil em diversos setores, como por exemplo a siderurgia, papel e celulose, saneamento e recursos renováveis.

Como resposta a essas preocupações tem-se o interesse por combustíveis de fontes alternativas tais como etanol, biodiesel e o hidrogênio, preferencialmente derivados de fontes renováveis, como os materiais lignocelulósicos.

Os materiais lignocelulósicos representam uma abundante fonte de energia renovável em todo o mundo e está disponível na forma de subprodutos agrícolas e florestais. $O$ desenvolvimento de tecnologias que visam o aproveitamento destes subprodutos mostra um importante avanço tecnológico.

No Brasil, uma das fontes renováveis mais abundantes é o bagaço de cana-de-açúcar, um resíduo lignocelulósico facilmente produzido e de baixo custo. Estas vantagens do bagaço de cana faz com que ele se sobressaia na 
corrida para produção de etanol de segunda geração, ou seja, tecnologias para produzir etanol a partir da biomassa lignocelulóstica

O etanol é utilizado principalmente como combustível, (um dos poucos obtidos de fonte renovável no mundo), assim como também é utilizado como insumo industrial com grande diversidade de aplicações podendo ser produzido a partir de diferentes fontes de matéria prima. Dentre as principais matérias-primas utilizadas atualmente para a produção de etanol, encontra-se a cana- de -açúcar, o amido de milho e o açúcar de beterraba. Esses produtos agrícolas têm grandes aplicações alimentícias, fazendo com que haja uma grande demanda por novas alternativas para a produção de etanol. Portanto, o uso futuro do etanol em larga escala pode ser baseado na produção de materiais lignocelulósicos.

Resíduos como aparas de madeira, bagaço de cana, sabugo de milho, palha de casca de arroz, cavacos de eucalipto, os quais são formados por celulose e hemicelulose, podendo ser convertidos em açúcares quando submetidos a reações de hidrólise, (um processo químico ou enzimático de quebra das ligações entre os contituintes da celulose e hemicelulose), tais como açúcares que podem ser convertidos em etanol. Uma grande vantagem dessa abordagem seria reduzir a competição entre biocombustíveis e alimentos, produzindo, no caso do aproveitamento do bagaço, mais etanol por área plantada. Neste contexto os materiais lignocelulósicos por representar uma abundante fonte de energia renovável em todo o mundo, apresentando grande potencial de uso como matéria prima em processos industriais para produção de bens de consumo diversos como combustíveis, insumos químicos e alimentos.

O melhor aproveitamento da produção de etanol seria uma hidrólise eficiente e com baixos custos, com a utilização dos açúcares resultantes, sem subprodutos. Entre esses açúcares, a xilose é a pentose predominante na fração hemicelulósica do hidrolisado de certos materiais lignocelulósicos, como o bagaço de cana-de-açúcar, sendo o segundo mais abundante neste material, abaixo apenas da glicose, o que faz da bioconversão da xilose em etanol uma matéria prima potencial a partir desta biomassa lignocelulósica e para essa conversão, alguns fatores devem ser estudados, de modo a serem otimizados. 
A bioconversão da xilose é regulada por diversos fatores como $\mathrm{pH}$, temperatura, aeração, concentração de substrato e suplementação nutricional.

A fermentação em meios sintéticos apresenta resultados promissores, porém a utilização dos hidrolisados hemicelulósicos como substratos, devido a sua variada composição, necessita de maiores estudos sobre os efeitos de diversos fatores, tais como pH, temperatura, aeração, suplementação nutricional e agitação.

O estudo envolvendo o aproveitamento de materiais lignocelulósicos é uma das linhas de pesquisa desenvolvidas na Área de Conversão de Biomassa do Grupo de Microbiologia Aplicada e Bioprocessos (GMBio) da Escola de Engenharia de Lorena (EEL) da Universidade de São Paulo(USP), que visa o aproveitamento de açúcares presentes na fração hemicelulósica do bagaço de cana-de-açúcar através de processos fermentativos utilizando as leveduras, como a Pichia stipitis e Candida guilliermondii, na produção de produtos de interesses como etanol e xilitol.

Neste trabalho utilizou-se a levedura Spathaspora arborariae UFMG-HM19, recém-isolada da Mata Atlântica brasileira e cedida pelo grupo de pesquisa do Departamento de Microbiologia, do Instituto de Ciências Biológicas da Universidade Federal de Minas Gerais (UFMG). Este trabalho é pioneiro no estudo fermentativo desta levedura para produção de etanol em hidrolisado hemicelulósico de bagaço de cana-de-açúcar. Os estudos iniciais dessa levedura mostraram que a mesma possui uma capacidade de fermentar a xilose presente na fração hemicelulósica do bagaço de cana, conseguindo alcançar o fator de rendimento teórico $(0,51 \mathrm{~g} / \mathrm{g})$ em meio sintético. Como não há um organismo definido para a fermentação de xilose na produção de etanol, faz-se necessário a exploração de novos organismos, de modo a desenvolver melhores condições para a expansão da produção.

A proposta deste trabalho envolve inicialmente a avaliação da produção de etanol através dessa levedura, em hidrolisado hemicelulósico de bagaço de canade-açúcar em função da suplementação nutricional do meio hidrolisado. Em uma segunda etapa é avaliada a bioconversão em etanol frente à variação de 
importantes parâmetros fermentativos, como temperatura e $\mathrm{pH}$ e concentração inicial de açúcares desse hidrolisado. 


\section{REVISÃO BIBLIOGRÁFICA}

\subsection{Materiais Lignocelulósicos}

\subsubsection{Composição}

Os materiais lignocelulósicos são um grande montante da massa residual de processos agroindustriais, compostos principalmente de celulose, hemicelulose e lignina em diferentes proporções, de acordo com diversos fatores, tanto biológicos, como espécie do vegetal, variabilidade genética, tecidos específicos; quanto ambientais como, por exemplo, condições de crescimento do vegetal (GOLDSTEIN, 1981; WYMAN, 1999; FENGEL, WEGENER, 1989).

Os materiais lignocelulósicos, devido a sua abundância de compostos orgânicos, tais como açúcares e compostos fenólicos, apresentam grande potencial como matéria-prima em processos industriais para produção de combustível, alimentos, insumos químicos, enzimas e bens de consumo diversos (LATIF, RAJOCA, 2001). Também representam uma das fontes de energia renováveis mais abundantes do planeta. Dentre os subprodutos agrícolas, destaca-se, no Brasil o bagaço da cana-de-açúcar, que é abundante em diversas regiões do país.

O aproveitamento destes materiais está relacionado com a sua constituição, essencialmente de celulose, hemicelulose, lignina, uma pequena quantidade de extrativos e cinzas. As proporções de todos os constituintes variam entre cada espécie vegetal (KUHAD, SINGH, 1993). A Figura 2.1 apresenta a composição aproximada de alguns materiais lignocelulósicos encontrados na natureza. 
Tabela 2-1. Composição de alguns materiais lignocelulósicos (*NA - não avaliados) (adaptado de SANCHES, 2009).

\begin{tabular}{lllll}
\hline Resíduos Ignocelulósicos & $\begin{array}{l}\text { Lignina } \\
(\%)\end{array}$ & $\begin{array}{l}\text { Hemicelulose } \\
(\%)\end{array}$ & $\begin{array}{l}\text { Celulose } \\
(\%)\end{array}$ & $\begin{array}{l}\text { Cinzas } \\
(\%)\end{array}$ \\
\hline Cascas de noz & $30-40$ & $25-30$ & $25-30$ & $\mathrm{NA}^{*}$ \\
Sabugos de milho & 15 & 35 & 45 & 1.36 \\
Palha de arroz & 18 & 24 & 32.1 & $\mathrm{NA}^{*}$ \\
Grama (valor médio) & $10-30$ & $25-50$ & $25-40$ & 1.5 \\
Bagaço de cana-de-açúcar & $19-24$ & $27-32$ & $32-44$ & $4.5-9$ \\
Palha de trigo & $16-21$ & $26-32$ & $29-35$ & $\mathrm{NA}$ \\
Palha de cevada & $14-15$ & $24-29$ & $31-34$ & $5-7$ \\
Palha de aveia preta & $16-19$ & $27-38$ & $31-37$ & $6-8$ \\
Palha de centeio & $16-19$ & $27-30$ & $33-35$ & $2-5$ \\
Bambu & $21-31$ & $15-26$ & $26-43$ & $1.7-5$ \\
Polpa de café & 18.8 & 46.3 & 35 & 8.2 \\
\hline
\end{tabular}

A lignina é uma macromolécula complexa, sua estrutura caracteriza-se como uma molécula aromática que é sintetizada a partir de precursores fenilpropanóicos e que pode pertencer a três classes, como: a guaiacil-lignina e a guaiacil-siringuil-lignina, que diferem no esqueleto fenilpropanóico (ADLER, 1977). Por possuir uma estrutura polifenólica ramificada, a lignina é responsável pela coesão entre fibras vegetais, assim como pela dureza nos materiais ignocelulósicos e pela proteção anti-microbiana, atuando como uma barreira contra a degradação causada pelos microorganismos, mas não é convertida em açúcares fermentescíveis (GOLDSTEIN, 1981). Assim, durante hidrólise dos materiais lignocelulósicos, são liberados compostos fenólicos, álcoois aromáticos 
e aldeídos, caracterizados como inibidores do metabolismo microbiano (ZALDIVAR et al, 2000).

A celulose, é formada por moléculas de glicose unidas por ligações $\beta$ $(1 \rightarrow 4)$. A molécula de celulose é linear e apresenta ligações de hidrogênio intra e intermoleculares. As ligações intramoleculares auxiliam na manutenção da rigidez da cadeia de celulose, enquanto que as intermoleculares mantêm as cadeias em um arranjo firme e compacto. Duas regiões distintas são visualizadas na molécula: a região cristalina, que apresenta moléculas altamente orientadas e resistência à degradação microbiana, e a região amorfa, onde há uma menor orientação entre as moléculas, sendo, portanto, facilmente hidrolisada (FENGEL, WEGENER, 1989).

A porção hemicelulóstica é formada por monômeros que estão presentes em grandes quantidades nos resíduos lignocelulósicos. São heteropolissacarídeos formados por cadeias lineares apresentando ramificações laterais, sendo compostas por hexoses (D-glicose, D-manose, D-galactose), pentoses (D-xilose, L- e D-arabinose) e ácido acético. Devido ao baixo grau de polimerização e baixa cristalinidade, a estabilidade química e térmica desta fração é menor do que da celulose tornando a fração hemicelulósica a mais facilmente hidrolisável do que a celulose (JEFFRIES, 1983), o que permite a utilização dos seus açúcares, como a D-xilose, para a produção de diferentes produtos de interesse, como, por exemplo, o xilitol e etanol (SANTOS et al., 2005a; SANTOS et al., 2005b).

A hemicelulose e a lignina juntas formam uma matriz em torno da celulose, e assim penetram nos espaços vazios entre as moléculas de celulose na região amorfa, contribuindo com o aumento na rigidez do vegetal.

\subsubsection{Processos de Pré-tratamento e Hidrólise}

Os materiais lignocelulósicos, devido as suas características, não permitem acessibilidade adequada aos seus componentes em seu estado natural, sendo 
necessário uma etapa de preparo para o meio fermentativo, como um prétratamento (MCMILLAN, 1994).

Diversos fatores afetam a hidrólise dos resíduos lignocelulósicos, como a porosidade do material, a cristalinidade da celulose e os conteúdos de lignina e hemicelulose (MCMILLAN, 1994). Portanto, uma etapa de pré-tratamento é conveniente para alterar as dimensões macro e microscópicas do resíduo e a sua estrutura (LASER et al., 2002; MOSIER et al., 2005), liberando dessa forma a fração hemicelulósica e celulósica para a hidrólise enzimática, como demonstrado na Figura 2.1.

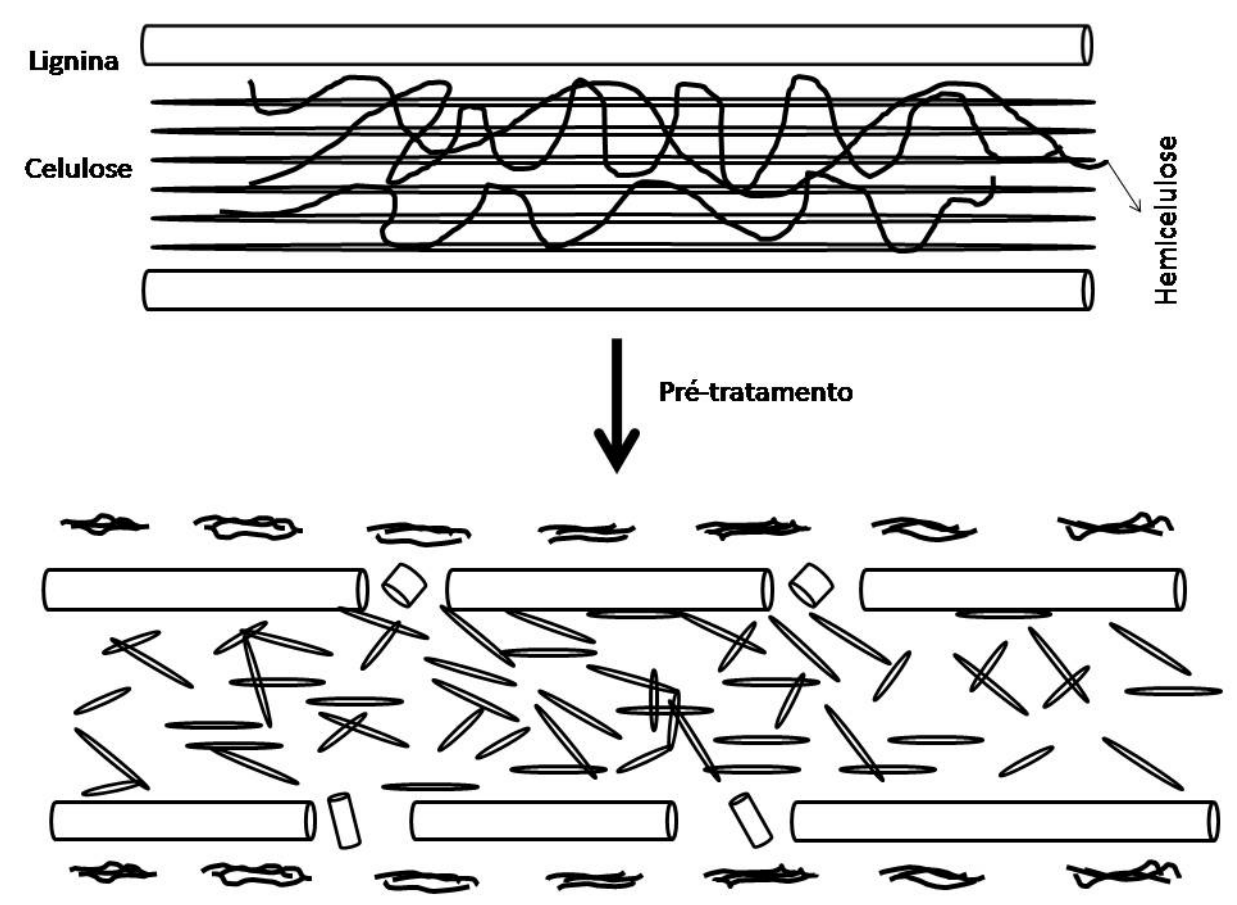

Figura 2-1Pré-tratamento da estrutura lignocelulósica do bagaço de cana-de-açúcar (Baseado em: USA, Departament of Energy, 2009).

Os processos de pré-tratamento são divididos em: mecânicos (moagem), físicos (vapor); físico-químicos (explosão a vapor), químicos (hidrólise ácida) e biológicos (biodegradação) (SUN, CHENG, 2002).

Os processos mecânicos, como a moagem, reduzem o tamanho das partículas, assim como a cristalinidade e causam a quebra de ligações de longas cadeias moleculares (LASER et al. 2002). 
O processo de tratamento com vapor, um dos tipos de tratamento físicoquímicos, envolve o aquecimento do material a uma temperatura entre 120 e 250 ${ }^{\circ} \mathrm{C}$, promovendo uma hidrólise parcial da fração hemicelulósica e um aumento no tamanho dos poros do material (MOSIER, et al. 2005). A explosão a vapor, outro tratamento físico-químico, envolve o aquecimento do material lignocelulósico numa faixa de temperatura entre $160-260{ }^{\circ} \mathrm{C}$, por segundos ou até poucos minutos, seguindo-se de rápida descompressão. Esta descompressão provoca quebras mais acentuadas na estrutura dos materiais lignocelulósicos. Esse processo promove abertura das fibras vegetais, solubilização da fração hemicelulósica em razão da hidrólise ocasionada pela ação de ácidos formados durante o tratamento, como por exemplo, o ácido acético derivado da hemicelulose, e despolimerização parcial da estrutura da lignina, deixando a celulose exposta para a ação enzimática. Os fatores que afetam este processo são o tempo de residência, temperatura, tamanho e conteúdo do material lignocelulósico (DUFF, MURRAY, 1996).

No processo biológico, como a biodegradação, são utilizados microorganismos, como bactérias e fungos, para degradar determinadas frações do material lignocelulósico. As vantagens deste tipo de pré-tratamento são a baixa energia requerida e a alta especificidade. Entretanto, a taxa de hidrólise é ainda considerada baixa (SUN, CHENG, 2002).

Após receber um pré-tratamento, o material lignocelulóstico pode, então, passar pelo processo de hidrólise. Diferentes métodos podem ser utilizados para a separação das frações (celulose, hemicelulose e lignina) e liberação dos açúcares monoméricos incluindo a hidrólise enzimática (GNANSOUNOU et al 2005; MOSIER et al., 2005; KUMAR et al. 2009), a hidrólise ácida (ZHAO et al.2008), e a hidrólise alcalina (DAWSON, BOOPATHY,2008).

O processo de hidrólise enzimática da celulose é conduzido por enzimas altamente específicas, liberando açúcares redutores, como a glicose. Utiliza-se um complexo de enzimas no processo de hidrólise, sendo elas as endoglucanases (endo-1,4-D-glucanohidrolase), que agem em regiões de baixa cristalinidade na fibra de celulose; exoglucanases (celobiohidrolase ou 1,4- $\beta$-Dglucanocelobiohidrolase), que liberam unidades de celobiose; e $\beta$-glicosidases, 
que hidrolisa a celobiose liberando, assim, moléculas de glicose (DUFF, MURRAY, 1996)

No processo de sacarificação e fermentação simultâneas, os açúcares redutores produzidos na hidrólise da celulose ou sacarificação são simultaneamente fermentados, reduzindo, assim, a inibição pelo produto durante a hidrólise enzimática (SUN, CHENG, 2002). Existem outras enzimas que agem sobre a fração hemicelulósica, como a glicoronidase, acetilesterase, xilanase, $\beta$ xilosidade, galactomananase e glucomananase (DUFF, MURRAY, 1996).

No processo de hidrólise ácida dos materiais ignocelulósicos, o uso de ácidos concentrados, como o ácido sulfúrico e o clorídrico, pode levar à ocorrência de corrosão, além do risco no manuseio do produto(PARISI, 1989). Desta forma, o emprego de ácidos diluídos tem mostrado eficiência ao fornecer soluções com alta concentração de açúcares, baixas concentrações de compostos inibitórios, sem causar os problemas acarretados pelos ácidos concentrados (PARISI, 1989).

O processo consiste em hidrolisar a fração hemicelulósica, sendo que as frações lignina e celulose permanecem quase inalteradas. Alguns ácidos diluídos utilizados para esse tipo de hidrólise são: ácido sulfúrico, acético e nítrico.

O produto da hidrólise é uma solução contendo principalmente açúcares, como xilose, glicose e arabinose e subprodutos como, por exemplo, oligômeros, furfural e ácido acético são também liberados após o procedimento de hidrólise (TEIXEIRA et al, 1999). A temperatura de hidrólise, o tempo e a concentração do ácido influenciam na formação de inibidores do crescimento microbiano (BUSTOS et al., 2003; RODRÍGUEZ-CHONG et al., 2004).

$\mathrm{Na}$ hidrólise alcalina ocorre o rompimento nas ligações éster entre hemiceluloses e lignina, sendo que o efeito vai depender do conteúdo de lignina do material lignocelulósico. $\mathrm{O}$ uso de $\mathrm{NaOH}$ diluído causa uma intumescência no material, aumenta a área de superfície interna, diminui o grau de polimerização e a cristalinidade e leva a ruptura da estrutura da lignina, assim como um aumento na porosidade do material quando as ligações éster são rompidas. (SUN, CHENG, 2002; SUN et al., 2004). 


\subsection{Bagaço da Cana-de-Açúcar}

Atualmente o Brasil é um dos maiores produtores de cana-de-açúcar do mundo. Segundo o Ministério da Agricultura, em 2011 a estimativa é que a indústria sucroalcooleira deverá atingir uma safra com 642 milhões de toneladas de cana-de-açúcar processadas, este volume representa um aumento de 2,9\% do obtido na safra passada (CONAB, 2011). O bagaço produzido por esse montante é considerado um combustível não eficiente devido a variação de umidade do mesmo, sendo a maior parte utilizado pela própria indústria sucro-alcooleira como fonte de energia (CONAB, 2009).

O Estado de São Paulo continua liderando o ranking produtivo do país, com uma projeção que varia entre 360,41 a 367,69 milhões de toneladas de canade-açúcar. Isso representa aproximadamente $58 \%$ da cana processada em todo o Brasil (CONAB 2009). Do total produzido, cerca de $50 \%$ é destinado à produção de açúcar, 39\% para o álcool e 10\% destina-se à fabricação de outros produtos, como cachaça, rapadura e açúcar mascavo (CONAB, 2009).

O processamento industrial da cana-de-açúcar proporciona uma total utilização da matéria-prima, ou seja, além da produção de açúcar e álcool, os subprodutos, tais como o vinhoto e o bagaço, podem ser aproveitados como fontes geradoras de energia ou na produção de adubos, papel e plásticos biodegradáveis (IEA - SP, 2009).

O bagaço da cana-de-açúcar é um dos principais subprodutos da indústria sucroalcooleira (PANDEY et al., 2000), sendo caracterizado como um resíduo fibroso que é produzido após a moagem e extração do xarope da cana-de-açúcar, contendo cerca de $40-45 \%$ de celulose, 30-35\% de hemicelulose e $25 \%$ de lignina (ANSELMO FILHO, BADR, 2004; PANDEY et al., 2000).

No processamento da cana-de-açúcar são gerados cerca de $270 \mathrm{~kg}$ de bagaço úmido a partir de uma tonelada de matéria-prima sendo que, $50 \%$ do total de bagaço úmido destina-se à demanda de energia da usina sucroalcooleira (FROLLINI, PIMENTA, 1997). 
Numa primeira fase, o bagaço substituiu a lenha para a geração de calor nas usinas. Atualmente, o vapor produzido através da queima do bagaço é utilizado para gerar três tipos de energia: térmica, transferindo calor para os processos industriais; mecânica, na movimentação de máquinas; e elétrica, através da movimentação de turbinas, suprindo o consumo energético do parque industrial (COSTA, 2006).

Através de um mecanismo de hidrólise, a fração hemicelulósica é separada e os açúcares, como xilose, glicose e arabinose são liberados, podendo ser utilizados em diversos processos biotecnológicos (LAVARACK et al., 2002; MOSIER et al., 2005; PANDEY et al., 2000), como por exemplo, processos fermentativos para obtenção de butanodiol (JASEN; FLICKINGER; TSAO, 2004); xilitol (RODRIGUES et al. 2008) e etanol (SARROUTH et al, 2007).

\subsection{Etanol}

\subsubsection{Propriedades e Aplicações}

A utilização do etanol está concentrada, em escala mundial, na geração de energia, em sua mistura com a gasolina ou simplesmente desidratado, exercendo um papel considerável na matriz energética mundial (LIN, TANAKA 2006). Contudo, a utilização do etanol é mais que simplesmente combustível: desde sua descoberta, está diretamente ligado ao cotidiano do homem, sendo a industria de alimentos a pioneira em seu uso. O etanol é utilizado em diversos segmentos industriais, como solvente, componente de formulações farmacêuticas, na industria de higiene e limpeza, matéria prima para processos de produção de ácidos orgânicos, éteres, ésteres, óxidos, hidrocarbonetos e produção de biopolímeros (LIN, TANAKA 2006), podendo ser de origem química, petroquímica ou biotecnológica. 


\subsubsection{Produção}

\subsubsection{Processo Químico}

O etanol pode ser produzido por via química através de hidratação, utilizando etileno como substrato catalisado por um ácido forte como, por exemplo, ácido sulfúrico. Nesse processo, o etileno reage formando sulfato de etila, que é posteriormente hidrolisado, gerando etanol e liberando ácido sulfúrico, obtendo-se assim o produto e a regeneração do catalisador (SCHLITTLER, 2006). A reação pode ser observada na equação 2.1.

$$
\begin{gathered}
\mathrm{C}_{2} \mathrm{H}_{4}+\mathrm{H}_{2} \mathrm{SO}_{4} \rightarrow \mathrm{CH}_{3} \mathrm{CH}_{2} \mathrm{SO}_{4} \\
\mathrm{CH}_{3} \mathrm{CH}_{2} \mathrm{SO}_{4}+\mathrm{H}_{2} \mathrm{O} \rightarrow \mathrm{CH}_{3} \mathrm{CH}_{2} \mathrm{OH}+\mathrm{H}_{2} \mathrm{SO}_{4}
\end{gathered}
$$

\subsubsection{Processo Microbiológico}

Muitos microorganismos são capazes de utilizar açúcares para produzir, através de processo fermentativo, etanol (OLSSON, HAHN-HÄGERDAL, 1996). Atualmente, o organismo mais utilizado para produção de etanol por meio de fermentação é a levedura Saccharomyces cerevisiae, utilizando glicose, devido a sua tolerância a altas concentrações de açúcar e seu elevado rendimento de etanol (MILLATI et al., 2004). Contudo, essa levedura, em sua forma selvagem, é somente capaz de fermentar hexoses, não possuindo o metabolismo para produzir etanol através de pentoses, como a xilose e arabinose, principais constituintes da porção hemicelulóstica dos materiais ignocelulósicos (HAMACHER et al., 2002; NAKAMURA et al., 2001).

Com a crescente demanda de utilização da biomassa vegetal como substratos de fermentação, faz-se necessário o estudo de microorganismos que sejam capazes de assimilar e fermentar pentoses, tais como as leveduras do gênero Candida, Pichia, Schizosaccharomyces, Kluyveromyces, Spatasphora e Pachysolen, os fungos filamentosos Fusarium, Mucor, Monilia e Paecilomyces e 
as bactérias Clostridium, Bacillus, Bacteroides, Thermoanaerobacter e Erwinia. Dentre estes organismos, destacam-se os organismos Candida shehatae, Pichia stiptis e Fusarium oxysporum, devido aos altos rendimentos (maiores que $0,45 \mathrm{~g}$ de etanol/g xilose) e produtividade (maiores que 0,17 g.l-1.h) (BETANCUR, 2005, MILLATI et. al, 2004; HAHN-HAGERDAL et al., 1994).

A via fermentativa utilizada pelas leveduras para a conversão de xilose em etanol (Figura 2.3) inicia-se com o transporte de xilose para o citossol celular através da membrana plasmática (JEFFRIES, 1983; HAHN-HAGERDAL et al.,1994; WINKELHAUSEN, KUSMANOVA 1998). Após o transporte, a xilose é reduzida a xilitol pela enzima xilose redutase (XR, EC 1.1.1.2.1.), na presença de $\mathrm{NADH}$ e/ou NADPH. Essa reação é seguida pela oxidação de xilitol em xilulose catalisada pela enzima xilitol desidrogenase - XDH (E.C.1.1.1.9.), que pode ser $\mathrm{NAD}^{+}$dependente ou, mais raramente, $\mathrm{NADP}^{+}$dependente. A xilulose pode então ser submetida a uma fosforilação, transfosrmando-se em xilulose 5-fosfato, molécula que pode ser convertida, através de reações não oxidativas da via hexose monofosfato (ou via das pentoses monofosfato), a gliceraldeído 3-fosfato e frutose 6-fosfato, podendo então ser metabolizados pela via Embden-MeyerhoffParnas, a qual está conectada a outras, como o ciclo de Krebs e as reações de fermentação alcoólica, ilustradas na Figura 2.2. 


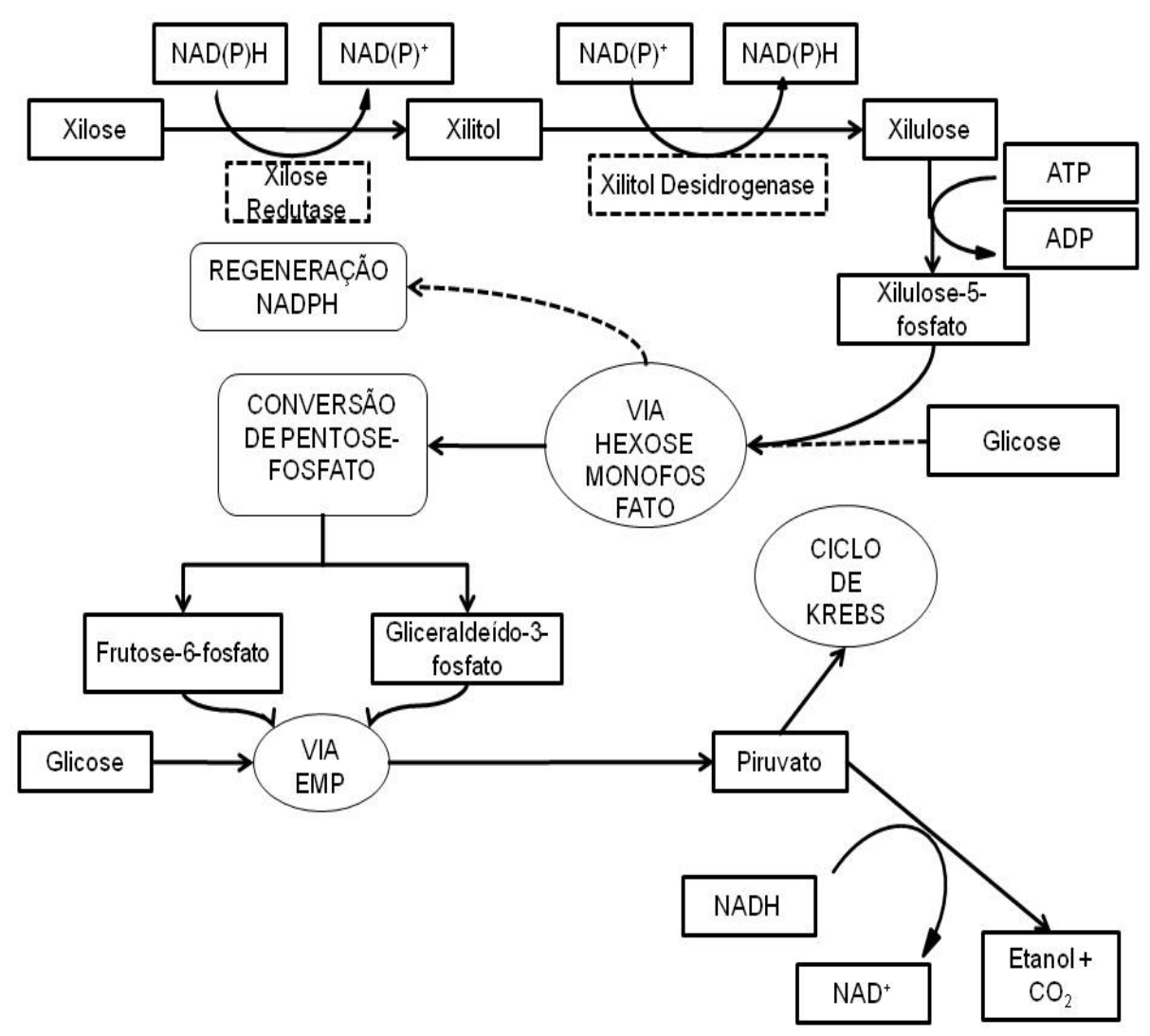

Figura 2-2 Metabolismo de xilose por leveduras (esquema simplificado) Baseado em Parajó et al (1998a)

Além da utilização de microrganismos selvagens para fermentação de pentoses, outra estratégia de produção de etanol a partir de pentoses é a utilização de microrganismos recombinantes (DAVIS et al., 2005; JIN et al., 2004; ELIASSON et al., 2000), que apresentam duas difierentes estratégias para permitir a fermentação de pentoses, em especial xilose e arabinose em etanol. Uma das linhas de pesquisa tem como foco a modificação de organismos tradicionais em fermentação de etanol para obterem a capacidade de metabolizar as pentoses (Saccharomyces cerevisiae e Zymomonas mobilis). A segunda linha de pesquisa visa à introdução de genes para produção de etanol em organismos capazes de metabolizar pentoses, como Escherichia coli, Klebsiella oxytoca e Erwinia ssp. (DUMSDAY et al., 1997; SAHA, 2003). Embora a eficiência dos microrganismos recombinantes seja grande, a utilização dos mesmos em processos industriais ainda não é viável por necessitar, em alguns casos, meios de cultura complexos, o que pode encarecer o processo (DUMSDAY et al., 1997). 
Há uma grande relação entre a especificidade da enzima XR aos cofatores NADH ou NADPH e o acúmulo de xilitol no citoplasma da levedura, com seu posterior transporte para o meio de cultivo (BRUINENBERG et al, 1984; SILVA et al , 1996a; WILSON et al, 2003). Quando a atividade da XR depende de NADH ou $\mathrm{NADPH}$, o cofator $\mathrm{NAD}^{+}$utilizado na redução da xilose a xilitol pode ser recuperado na etapa seguinte, seja em condições anaeróbias ou de limitação de oxigênio. Sob tais condições, o principal produto do metabolismo de xilose é o etanol, não havendo acúmulo de xilitol. Quando a atividade da XR de um dado microorganismo depende apenas de NADPH, sob condições de limitação de oxigênio observa-se acúmulo de xilitol, uma vez que, nestas condições, a capacidade da cadeia respiratória de recuperar o cofator oxidado é baixa, acarretando a diminuição da atividade da enzima $\mathrm{XDH}$, portanto, diminuindo a velocidade de transformação (JEFFRIES, 1983; HAHN-HAGERDAL E al.,1994; WINKELHAUSEN, KUSMANOVA 1998).

\subsection{Spathaspora arborariae}

A levedura, recentemente identificada como Spathaspora arborariae (Figura 2.3), mostrou-se como potencial fonte para os organismos recombinantes, contudo, seu alto rendimento de etanol (0,51 $\mathrm{g}$ de etanol $/ \mathrm{g}$ xilose) tornou-a interessante a utilização da espécie selvagem em hidrolisados hemicelulósticos, por sua capacidade de fermentar tanto glicose quanto xilose, ambos presentes no meio hemicelulóstico. Em ensaio preliminar em meio sintético contendo $20 \mathrm{~g} \cdot \mathrm{L}^{-1}$, observou-se total consumo de xilose em menos de um dia de fermentação, demonstrando a capacidade do organismo em fermentar o açúcar abundante em cana-de-açúcar (CADETE, 2009). 


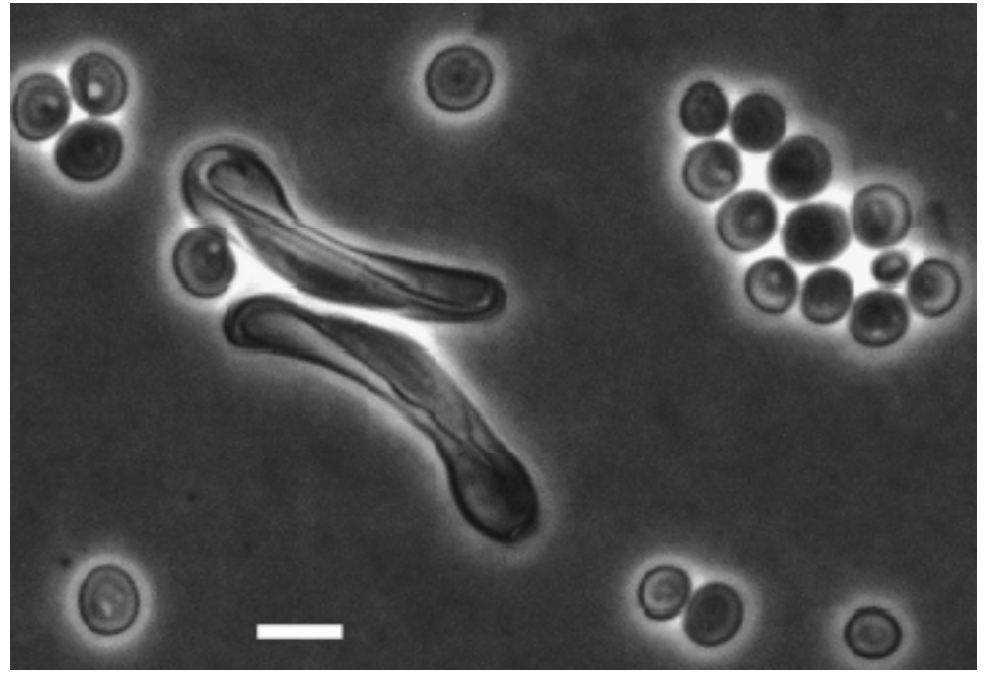

Figura 2-3 Células e ascos de Spathaspora arborariae em Agar V8 diluído após 3 dias a $20^{\circ} \mathrm{C}$. Barra de escala $=5$ um (retirado de CADETE, 2009)

Esse organismo foi isolado de amostras obtidas em madeiras decompostas provenientes do Parque Nacional da Serra do Cipó, localizado na Serra do Espinhaço, dentro do estado de Minas Gerais. O clima da região é tropical de altitude, com uma média de temperatura entre 17 e $18^{\circ} \mathrm{C}$ e o bioma predominante é cerrado, apresentando também campos rupestres (CADETE, 2009).

\subsection{Principais Parâmetros na Fermentação de Etanol}

De modo a melhorar o processo de produção biotecnológica de etanol, muitos estudos vêm sendo realizados a partir de pentoses, relatados em Olsen \& Hanh-Hagerdal (1996). O foco desses trabalhos foi o estudo dos diversos parâmetros importantes para otimização da fermentação, como pH, temperatura, aeração, agitação, suplementação, meios de cultivo do inóculo, e tolerância aos produtos formados.

\subsection{1 pH}

O pH é um parâmetro significativo devido a sua importância tanto no controle da contaminação bacteriana quanto no seu efeito sobre o crescimento da 
levedura e a cinética de fermentação. As leveduras crescem melhor em meios ácidos com pH entre 3,5 e 3,8 porém, de acordo com a espécie, o limite de $\mathrm{pH}$ pode se situar entre pH 2,2 e 8,0 (PELCZAR et. al 1980). Contudo, o pH de fermentação em hidrolisados hemicelulósicos não devem ser muito reduzidos, devido a toxidade do ácido acético em $\mathrm{pH}$ muito reduzido. $\mathrm{O}$ ácido acético, em um meio de ph inferior a 4,75, encontra-se na sua forma não dissociada, comportando-se de forma lipossolúvel, permitindo a entrada da substância pela membrana plasmática. No citoplasma, o pH fisiológico da levedura é superior a o pKa do ácido acético, dissociando em acetato e íons $\mathrm{H}^{+}$, causando um desequilibrio eletrolítico, que poderia ser uma consequência do desacoplamento da cadeia enzimática da ATPase ou pelo acumulo de ânions.

Estudos realizados com a Candida shehatae mostraram que a produção de etanol aumentou de 45 para 55 g.l-1 quando o pH aumentou de 4,5 para 6,0 (KASTNER et al.1996) ainda que o $\mathrm{pH}$ interno da célula se mantêm na faixa de 5,8 a 6,9, seja qual for o pH extracelular na faixa de 2 a 7 (MAIA, 1989). Contudo, baixos valores de $\mathrm{pH}$ tornam o meio mais agressivo, uma vez que exigem das leveduras um maior gasto de energia na manutenção do $\mathrm{pH}$ interno, além de afetar as proteínas, como as de transporte situados na membrana citoplasmática, que ficam expostas ao meio externo (MAIA, 1989). Na fermentação alcoólica, o estabelecimento e controle do $\mathrm{pH}$ do meio em valores inferiores a 5 é também considerado importante como meio para prevenir contaminação por bactérias láticas e acéticas (MAIA,1989). No geral, o pH ótimo para a produção de etanol pela levedura Sacharomyces cerevisiae encontra-se na faixa de $\mathrm{pH} 4$ a 5 . Neste caso, o aumento do pH para 7,0 observou-se uma diminuição no fator de conversão em etanol e aumento da produção de ácido acético (MAIA,1989). Roberto et al. (1994) demonstraram que a variação do pH inicial de fermentação entre 4,0 e 6,0 exerceu pouca influência sobre os parâmetros fermentativos por Pichia stipitis $\mathrm{Y} 7124$, obtendo-se nesta faixa de $\mathrm{pH} \mathrm{Y}_{\mathrm{p} / \mathrm{s}}$ entre 0,34 e 0,37 g/g, $\mathrm{Y}_{\mathrm{x} / \mathrm{s}}$ entre 0,11 e $0,14 \mathrm{~g} / \mathrm{g}$ e produtividades em etanol em torno de $0,90 \mathrm{~g} . \mathrm{l}-1$.h. 


\subsubsection{Temperatura}

A temperatura ótima de produção de etanol pelas espécies fermentadoras pentose como as leveduras Pichia e Candida, encontram-se na faixa de 30 a 32 ${ }^{\circ} \mathrm{C}$, a qual pode variar de acordo com a cepa, do tipo e concentração de substrato (du PREEZ, 1994). Slininger e Bothast (1990) avaliaram a faixa de temperatura capaz de favorecer o processo de produção de etanol a partir de xilose, a máxima produtividade e concentração de etanol foram obtidas pela levedura Pichia stipitis NRRL Y-7124 utilizando 40 g.l-1 de xilose em uma faixa de 23 e $30^{\circ} \mathrm{C} .$.

Um aumento da temperatura do meio pode acelerar 0 tempo de fermentação. Para as leveduras P. stipitis CBS 7126 e Candida shehatae CBS 2779 a máxima velocidade específica de crescimento celular, produtividade específica e produtividade volumétrica em etanol ocorre em $30^{\circ} \mathrm{C}$, entretanto, estes autores também constataram um tempo menor de fermentação nesta temperatura, e que para $P$. stipitis o fator de conversão em etanol permaneceu constante, em $0,42 \mathrm{~g} / \mathrm{g}$ até $33^{\circ} \mathrm{C}$ e apresentou decréscimo para 0,29 g/g após elevação da temperatura para $36^{\circ} \mathrm{C}($ DU PREEZ et al. 1986).

\subsubsection{Oxigênio}

O metabolismo aeróbio é necessário para a fermentação de xilose em etanol. Sob condições anaeróbias, uma grande fração da xilose é convertida para xilitol, e a produção de etanol correspondentemente é baixa (du PREEZ,1994). De acordo com Taniguchi et al. (1997), em fermentação anaeróbio Pichia stipitis CBS 5773 consumiu uma quantidade insignificante de xilose, não sendo capaz de produzir etanol, assim como níveis insuficientes de aeração na produção de etanol pela levedura Pichia stipitis NRRL Y-7124 levaram a um consumo lento de xilose. Todavia, níveis excessivos de aeração reduzem o rendimento devido ao crescimento celular elevado, sendo um nível de aeração adequado um parâmetro importante para atingir elevados valores de conversão. (NIGAM 2001a, 2001b, 2001c) 


\subsubsection{Suplementação Nutricional}

Os microorganismos retiram do meio ambiente todas as substâncias necessárias para a síntese celular e para obtenção de energia, variando de acordo com as cepas. Essas variações refletem as diferenças na capacidade de síntese dos organismos. A habilidade em usar diferentes compostos como fonte de energia e de sintetizar proteínas e compostos do citoplasma a partir de compostos inorgânicos depende da presença de uma série de enzimas. A falta ou a repressão de um ou mais genes que codificam a formação de uma destas enzimas reflete-se diretamente nas necessidades nutricionais da célula.

O nitrogênio representa de 10 a $15 \%$ do peso seco das células. É o componente básico na formação de aminoácidos que formam as proteínas, assimilado sob forma amoniacal. Fontes de nitrogênio em outras formas que não a amoniacal são primeiramente transformadas em íons amônio dentro da célula (CARMOUZE, 1994). Muitas substâncias servem como fonte de nitrogênio: fontes inorgânicas de nitrogênio como $\mathrm{NH}_{4} \mathrm{Cl},\left(\mathrm{NH}_{4}\right)_{2} \mathrm{SO}_{4}, \mathrm{NH}_{4} \mathrm{NO}_{3}, \mathrm{~N}_{2}$; e fontes orgânicas de nitrogênio: aminoácidos, proteínas, peptídeos, uréia, purinas e pirimidinas (ALEXANDER, 1994). O sulfato de amônio pode servir como fonte de nitrogênio inorgânico, favorecendo o crescimento de leveduras (CANETTIERI, 2002).

Contudo, existe uma grande disponibilidade de fontes de nitrogênio orgânico de grande aplicação em bioprocessos industriais, tanto simples como a uréia, quanto complexas, como o farelo de arroz e o extrato de levedura. Dentre as principais fontes de nitrogênio complexas empregadas em bioprocessos, o extrato de levedura tem sido um dos mais utilizados em desenvolvimento de pesquisa por ter uma composição rica em vitaminas do complexo $B$ e aminoácidos (PEREIRA Jr. et al, 2008), sendo que vitaminas e minerais, são necessários como micronutrientes de leveduras para facilitar as reações bioquímicas (KOTARSKA, 2006) .

Os elementos minerais também são necessários, mas em concentrações da ordem de miligramas por litro (PELCZAR et al., 1996). Os íons metálicos (como $\mathrm{K}^{+}, \mathrm{Mg}^{2+}, \mathrm{Ca}^{2+}$ e $\mathrm{Zn}^{2+}$ ) podem mudar a velocidade da glicólise e a conversão de 
piruvato a etanol dando um impacto significante no progresso e eficiência da fermentação. Dentre os minerais destacam-se o magnésio, envolvido em muitas funções fisiológicas como de crescimento de leveduras, divisão celular e atividade de enzima, e tem um papel importante na proteção celular a níveis tóxicos de etanol (ALEXANDRER, 1994). Zinco é um elemento necessário em várias atividades enzimáticas relacionadas com as enzimas álcool desidrodrogenase, aldolase, fosfatase alcalina, DNA e RNA-polimerase (MAYALAGU et al, 1997). Estes em meio de fermentação são fatores importantes com efeito significativo sobre a fisiologia de leveduras e produção de etanol (BIRCH; WALKER, 2000), como magnésio influenciando diretamente a velocidade de crescimento das leveduras, o consumo de açúcar e a produção de etanol (REES; STEWART 1999). Em geral, é exigido pela levedura na faixa de concentração milimolar: a adição de $10 \mathrm{mM}$ de $\mathrm{Mg}^{2+}$ contribuiu para aumento da produção de etanol (REES; STEWART 1999). Na produção de etanol por S. Cerevisiae a relevância da adição de magnésio também é relatada. Elevadas concentrações de magnésio no meio (até $50 \mathrm{mM}$ ) resultaram em melhoria na viabilidade celular, em condições com elevadas concentrações de etanol, provavelmente por este ter exercido efeito protetor sobre as células, reduzindo a mortalidade celular (BIRCH; WALKER 2000). A suplementação de fermentações com $0.5 \mathrm{mM}$ de magnésio também prolongou a fase de crescimento exponencial, resultando em aumento da biomassa, e também na redução no declínio da atividade fermentativa (DOMBEK; INGRAM, 1986).

As células de leveduras também requerem vitaminas, como mio-inositol, ácido pantotênico, biotina e tiamina para o crescimento delas e aceleração de fermentação (ALFENORE et al. 2002). O ácido pantotênico é conhecido por ser um precursor da coenzima $A$, a qual está envolvida em muitos passos de metabolismo intermediário de carboidratos, gorduras e proteínas, também aumentando a tolerância da levedura ao etanol por estimular a síntese de lipídios (KOTARSKA et al., 2006). A biotina é um cofactor de muitas enzimas envolvido em reações de carboxilação, como metabolismo de aminoácido, biossíntese de ácidos graxos e metabolismo energético. Sua assimilação e armazenamento condicionam a velocidade de crescimento de leveduras e produção de etanol (ALFERONE et al. 2002). Mio-inositol também é fator de crescimento essencial 
para leveduras e contribui com a alta tolerância á etanol e aumento da viabilidade de celular (FURUKAWA et al.2004).

A suplementação do meio de fermentação é muito importante uma vez que prolonga sua viabilidade na fermentação (KOTARSKA et al., 2006; FURUKAWA et al.2004; BIRCH; WALKER,2000; RESS; STEWART 1999; DOMBEK; INGRAM 1986) 


\section{OBJETIVOS}

\subsection{Geral}

Contribuir para o desenvolvimento de uma tecnologia de obtenção de etanol por via biotecnológica, verificando o comportamento da levedura Spathaspora arborariae UFMG-HM.19.1 na fermentação de xilose em hidrolisado hemicelulósico de bagaço de cana-de-açúcar.

\subsection{Específicos}

Avaliar a necessidade de suplementação do hidrolisado hemicelulósico de bagaço de cana-de-açúcar para fermentação alcoólica dos açúcares xilose e glicose presentes neste hidrolisado.

Avaliar o efeito dos parâmetro temperatura, pH e concentração de inóculo na produção de etanol pela levedura em estudo.

Avaliar estatisticamente $o$ efeito entre os parametros estudados na produção de etanol. 


\section{MATERIAL E MÉTODOS}

\subsection{Obtenção e Preparo do Hidrolisado Hemicelulósico do Bagaço de Cana- de - açúcar}

O bagaço de cana-de-açúcar foi proveniente da usina São Francisco localizado em Sertãozinho, SP. Esse bagaço, após secagem ao ar livre, teve seu teor de umidade determinado. Após a secagem o bagaço foi hidrolisado, utilizando ácido sulfúrico diluído.

O hidrolisado hemicelulósico foi obtido em reator de aço inox com capacidade de 250 litros localizado no Departamento de Biotecnologia (LOT) da EEL/USP. O bagaço foi percolado com $\mathrm{H}_{2} \mathrm{SO}_{4} 98 \%$, em uma razão de $100 \mathrm{mg}$ $\mathrm{H}_{2} \mathrm{SO}_{4} / \mathrm{g}$ de matéria seca de bagaço, durante 30 minutos à temperatura de $121^{\circ} \mathrm{C}$, utilizando-se uma proporção de 1:10 entre massa seca de bagaço e volume da solução de $\mathrm{H}_{2} \mathrm{SO}_{4}$. Após o resfriamento, o hidrolisado foi centrifugado e estocado em bombonas de $50 \mathrm{~L}$ em câmara fria a $4^{\circ} \mathrm{C}$.

\subsection{Concentração e Tratamento do Hidrolisado Hemicelulósico}

O hidrolisado hemicelulósico de bagaço de cana obtido por hidrólise ácida passou por um processo de concentração a vácuo para redução em cinco vezes seu volume inicial sob temperatura de $70{ }^{\circ} \mathrm{C}$. Nesta etapa foi utilizado um concentrador a vácuo com capacidade volumétrica de $30 \mathrm{~L}$. A seguir, o hidrolisado foi tratado utilizando a detoxificação química por alteração de $\mathrm{pH}$, conforme metodologia descrita por ALVES et al. (1997). Esse procedimento envolve a elevação do $\mathrm{pH}$ inicial do hidrolisado para $\mathrm{pH}$ 7,0 pela adição de $\mathrm{CaO}$, com posterior redução de seu pH pela adição de ácido fosfórico concentrado para $\mathrm{pH}$ 5,5. A seguir foi adicionado ao hidrolisado $2,5 \%(\mathrm{~m} / \mathrm{v})$ de carvão ativo, mantendo-o sob agitação de 200 rpm em incubadora de movimento rotatório, a 30 ${ }^{\circ} \mathrm{C}$, por $1 \mathrm{~h}$. Nas etapas de alterações de pH bem como de remoção de carvão ativo, o hidrolisado foi filtrado a vácuo utilizando papel de filtro quantitativo. $\mathrm{O}$ 
hidrolisado concentrado e tratado foi autoclavado a 0,5 atm $\left(11{ }^{\circ} \mathrm{C}\right)$ por 15 minutos. Tanto o hidrolisado original como o hidrolisado concentrado, foram caracterizados quanto ao $\mathrm{pH}$ e concentrações de açúcares (glicose, xilose e arabinose), ácido acético, 5-hidroximetilfurfural e furfural.

\subsection{Micro-organismo}

Em todos os experimentos foi utilizada a linhagem de levedura Spathaspora arborariae UFMG-HM19.1A, mantida em meio ágar extrato de malte à $4^{\circ} \mathrm{C}$. Essa levedura foi recentemente isolada e cordialmente cedida pelo Profo. Dr. Carlos Augusto Rosa da Universidade Federal de Minas Gerais para realização dos ensaios fermentativos para a produção de etanol em hidrolisado hemicelulósico de bagaço de cana-de-açúcar.

\subsection{Preparo do Inóculo}

O inóculo da levedura Spathaspora arborariae UFMG-HM19.1A, foi

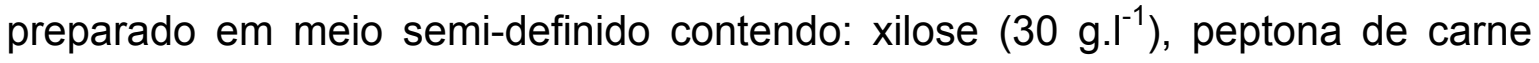
$(2 \% \mathrm{~m} / \mathrm{v})$ e extrato de levedura $(1 \% \mathrm{~m} / \mathrm{v})$. O cultivo foi conduzido em frascos Erlenmeyer de $125 \mathrm{~mL}$ contendo $25 \mathrm{~mL}$ de meio, em incubadora com movimento rotatório sob agitação de $200 \mathrm{rpm}$, à temperatura de $30{ }^{\circ} \mathrm{C}$ por 24 horas. As células foram recuperadas por centrifugação a 3000 X g por 15 min, lavadas e ressuspensas em água destilada esterilizada. Volumes adequados desta solução foram utilizados como inóculo, de forma a se obter uma concentração celular inicial indicada em cada experimento.

\subsection{Avaliação das Condições de aeração}


O meio de fermentação foi preparado com hidrolisado hemicelulósico de bagaço de cana-de-açúcar, sem nenhuma suplementação. As fermentações foram conduzidas de acordo com o planejamento fatorial completo $2^{3}$ com 3 repetições no ponto central (Tabelas 4.1 e 4.2). A Tabela 4.1 mostra os níveis de agitação e volume utilizados em seus valores codificados e reais. A Tabela 4.2 mostra o planejamento fatorial completo $2^{3}$ com 3 repetições no ponto central. As fermentações foram conduzidas em frascos Erlenmeyer contendo meio de fermentação e com 0,5 g.l-1 de inóculo. Os volume do Erlenmeyer e os volumes de hidrolisado utiizado em cada etapa do experimento estão especificados na Tabela 4.1. Esses frascos foram mantidos em incubadora de movimento rotatório sob agitação de acordo com seu nível e temperatura de $30^{\circ} \mathrm{C}$. Os ensaios foram executados em ordem aleatória para minimizar a ocorrência de erros sistemáticos. A análise estatística dos dados foi realizada utilizando o programa STATGRAPHICS, versão 15.2.111.

Tabela 4-1 Fatores e níveis avaliados no planejamento fatorial completo em seus níveis codificados e valores reais.

\begin{tabular}{lccc}
\hline \multicolumn{1}{c}{ Variáveis } & \multicolumn{3}{c}{ Níveis } \\
\hline & -1 & 0 & +1 \\
A - Agitação (rpm) & 100 & 150 & 200 \\
B - Volume de meio de & 25 & 35 & 50 \\
fermentação (ml) & & & \\
$\begin{array}{l}\text { C - Volume Erlenmeyer } \\
(\mathrm{ml})\end{array}$ & 125 & 200 & 250 \\
\hline
\end{tabular}


Tabela 4-2 Planejamento fatorial do tipo $2^{3}$, com 3 repetições no ponto central, para a avaliação do efeito da na produção de etanol a partir de hidrolisado de cana-de-açúcar pela levedura Spathaspora arborariae UFMG-HM19.1

\begin{tabular}{cccc}
\hline Experimentos & A & B & C \\
\hline $\mathbf{1}$ & -1 & -1 & -1 \\
2 & +1 & -1 & -1 \\
3 & -1 & +1 & -1 \\
4 & +1 & +1 & -1 \\
5 & -1 & -1 & +1 \\
6 & +1 & -1 & +1 \\
7 & -1 & +1 & +1 \\
8 & +1 & +1 & +1 \\
9 & 0 & 0 & 0 \\
10 & 0 & 0 & 0 \\
11 & 0 & 0 & 0 \\
\hline
\end{tabular}

\subsection{Avaliação da Suplementação do Meio de Cultivo}

O meio de fermentação foi preparado com hidrolisado hemicelulósico de bagaço de cana-de-açúcar adicionado de soluções nutrientes estoque de extrato de levedura (250 g.l-1), sulfato de magnésio (200 g.l-1) e sulfato de amônio (200 g.l-1) para obtenção das concentrações desejadas no hidrolisado conforme descrito no planejamento fatorial completo $2^{3}$ com 3 repetições no ponto central (Tabelas 4.3 e 4.4). A Tabela 4.3 mostra as concentrações dos nutrientes utilizados em seus valores codificados e reais. A Tabela 4.4 mostra o planejamento fatorial completo $2^{3}$ com 3 repetições no ponto central. As fermentações foram conduzidas em frascos Erlenmeyer de $125 \mathrm{~mL}$, contendo 25 $\mathrm{ml}$ de meio de fermentação e $0,5 \mathrm{~g} . \mathrm{l}-1$ de inóculo. Esses frascos foram mantidos 
em incubadora de movimento rotatório sob agitação de 200 rpm e temperatura de $30{ }^{\circ} \mathrm{C}$. Os ensaios foram executados em ordem aleatória para minimizar a ocorrência de erros sistemáticos. A análise estatística dos dados foi realizada utilizando do programa STATGRAPHICS, versão 15.2.111.

Tabela 4-3 Fatores e níveis avaliados no planejamento fatorial completo, em seus níveis codificados e valores reais.

\begin{tabular}{lccc}
\hline \multicolumn{1}{c}{ Variáveis (g.I-1) } & Níveis & +1 \\
\hline & -1 & 0 & 5 \\
A - Sulfato de magnésio & 0 & 2,5 & 5 \\
B - Sulfato de amônio & 0 & 2,5 & 5 \\
C - Extrato de Levedura & 0 & 2,5 & 5 \\
\hline
\end{tabular}

Tabela 4-4 Planejamento fatorial do tipo $2^{2}$, com 3 repetições no ponto central, para a avaliação do efeito da suplementação do hidrolisado com nutrientes, na produção de etanol pela levedura Spathaspora arborariae

\begin{tabular}{cccc}
\hline Experimentos & A & B & C \\
\hline $\mathbf{1}$ & -1 & -1 & -1 \\
$\mathbf{2}$ & +1 & -1 & -1 \\
$\mathbf{3}$ & -1 & +1 & -1 \\
$\mathbf{4}$ & +1 & +1 & -1 \\
$\mathbf{5}$ & -1 & -1 & +1 \\
$\mathbf{6}$ & +1 & -1 & +1 \\
7 & -1 & +1 & +1 \\
$\mathbf{8}$ & +1 & +1 & +1 \\
9 & 0 & 0 & 0 \\
10 & 0 & 0 & 0 \\
11 & 0 & 0 & 0 \\
\hline
\end{tabular}

\subsection{Avaliação dos Parâmetros da Fermentação}


Para avaliação dos parâmetros fermentativos foi utilizado a fração hemicelulósica do hidrolisado hemicelulóstico de bagaço de cana-de-açúcar, previamente tratado pelos métodos descritors nos itens 4.1 a 4.2. As fermentações foram conduzidas utilizando um planejamento fatorial $2^{2}$ com 3 repetições no ponto central, mostrado na Tabela 4-5, utilizando como fatores a temperatura, $\mathrm{o} \mathrm{pH}$ e a concentração de inóculo. As fermentações foram conduzidas em frascos Erlenmeyer de $125 \mathrm{~mL}$, contendo $25 \mathrm{ml}$ de meio de fermentação. Esses frascos foram mantidos em incubadora de movimento rotatório (modelo: G25KC, New Brunswick) sob agitação de 200 rpm. Os ensaios foram executados em ordem aleatória para minimizar a ocorrência de erros sistemáticos. A análise estatística dos dados foi feita utilizando o programa STATGRAPHICS, versão 15.2.11

Tabela 4-5 Níveis dos fatores utilizados no planejamento fatorial fracionário $2^{3}$ três repetições do ponto central em seus níveis codificados e valores reais.

\begin{tabular}{lccc}
\hline \multicolumn{1}{c}{ Variáveis } & \multicolumn{3}{c}{ Níveis } \\
\hline & -1 & 0 & +1 \\
A - Temperatura $\left({ }^{\circ} \mathrm{C}\right)$ & 30 & 35 & 40 \\
B - pH & 4 & 5 & 6 \\
C - Concentração de Inóculo (g.l-1) & 0,5 & 0,75 & 1,0 \\
\hline
\end{tabular}


Tabela 4-6 Planejamento fatorial do tipo $2^{2}$, com 3 repetições no ponto central, para a avaliação do efeito dos parametros fermentativos na produção de etanol pela levedura Spathaspora arborariae UFMG-HM19.1

\begin{tabular}{cccc}
\hline Experimentos & A & B & C \\
\hline $\mathbf{1}$ & -1 & -1 & -1 \\
2 & +1 & -1 & -1 \\
3 & -1 & +1 & -1 \\
4 & +1 & +1 & -1 \\
5 & -1 & -1 & +1 \\
6 & +1 & -1 & +1 \\
7 & -1 & +1 & +1 \\
8 & +1 & +1 & +1 \\
9 & 0 & 0 & 0 \\
10 & 0 & 0 & 0 \\
11 & 0 & 0 & 0 \\
\hline
\end{tabular}

\subsection{Métodos Analíticos}

4.8.1 Determinação da concentração de açúcares, ácido acético, glicerol e etanol

As concentrações de glicose, xilose, arabinose, xilitol, ácido acético, glicerol e etanol foram determinadas por cromatografia liquida de alta eficiência (CLAE). As amostras foram previamente diluídas e filtradas em filtro Sep Pak C18 e analisadas utilizando-se as seguintes condições: coluna BIO-RAD AMINEX HPX-87H (300 X 7,8 mm) mantida à temperatura de $45^{\circ} \mathrm{C}$; volume de injeção de $20 \mu \mathrm{l}$; detector de índice de refração Waters 410; fase móvel $\mathrm{H}_{2} \mathrm{SO}_{4}$ 0,01 N e fluxo de $0,6 \mathrm{ml} / \mathrm{min}$. 


\subsubsection{Determinação da concentração de furfural e hidroximetilfurfural}

Para a análise do teor de furfural e hidroximetilfurfural, as amostras foram previamente filtradas em membrana Minisart e injetadas no cromatógrafo, utilizando-se as seguintes condições: coluna RP $18(200 \times$ 4,6mm $)$ mantida à temperatura de $25^{\circ} \mathrm{C}$; volume de injeção de $20 \mu$; detector de ultravioleta Waters (276 nm); fase móvel acetonitrila/água 1:8 com 1\% de ácido acético e fluxo de 0,9 $\mathrm{ml} / \mathrm{min}$.

\subsubsection{Determinação da concentração celular}

A concentração celular no meio de fermentação foi determinada pela leitura da absorbância a $600 \mathrm{~nm}$ em espectrofotômetro BECKMAN DU 640B e correlacionada com a massa seca de células (g.l-1) por meio de uma curva de calibração previamente construída. O branco utilizado foi o meio de fermentação sem células diluido na mesma proporção do meio de fermentação com células. $O$ restante das amostras coletadas foram centrifugadas a $3000 \mathrm{Xg}$ por $10 \mathrm{~min}$. $\mathrm{O}$ sobrenadante foi armazenados em freezer para posterior análise em CLAE.

\subsubsection{Cálculo dos Parâmetros Fermentativos}

Equação 4-1 Fator de conversão de açúcares em etanol (Yp/s, $g_{\text {etanol produzido }} / g_{\text {xilose (ou }}$ glicose) consumida)

$$
\mathrm{Y}_{\mathrm{p} / \mathrm{s}}=\frac{\Delta \mathrm{P}}{-\Delta \mathrm{S}}=\frac{(\mathrm{Pf}-\mathrm{Pi})}{(\mathrm{Si}-\mathrm{Sf})}
$$

Sendo:

Pf: concentração final de etanol

Pi: concentração inicial de etanol 
Sf: concentração final de açúcar (Glicose ou Xilose)

Si: concentração inicial de açúcar (Glicose ou Xilose)

Equação 4-2 Eficiência de conversão de açúcares totais em etanol ( $\eta$ \%)

$$
\mathrm{n}(\%)=\frac{\mathrm{Y}_{\mathrm{p} / \mathrm{s}} \text { obtido }}{\mathrm{Y}_{\mathrm{p} / \mathrm{s}} \text { teórico }}
$$

Sendo:

Yp/s teórico= 0,51g etanol $/ \mathrm{g}$ açúcar

Equação 4-3 Produtividade em etanol (Qp, g etanol..$\left.^{-1} \cdot \mathrm{h}^{-1}\right)$

$$
Q p=\frac{(P f-P i)}{t}
$$

Sendo:

t: tempo de fermentação.

Equação 4-4 Percentagem de consumo de xilose (Y\%)

$$
\mathrm{Y} \%=\frac{(\mathrm{Si}-\mathrm{Sf})}{\mathrm{Si}} \times 100
$$

$\mathrm{Sf}=$ concentração final de açúcar (g.l-1)

Si = concentração inicial de açúcar (g.l-1) 


\section{RESULTADOS E DISCUSSÃO}

\subsection{Hidrólise}

O bagaço de cana-de-açúcar apresentou teor médio de umidade de $11 \%$, determinado em detector de umidade (LJ16 Moisture Analyzer, Mettler Toledo, São Paulo, Brasil) e foi submetido à hidrólise ácida realizada conforme item 4.1. O hidrolisado obtido após concentração (bruto) e aquele tratado foram submetidos à caracterização para determinar as concentrações de xilose, glicose, arabinose, ácido acético, furfural e hidroximetilfurfural (HMF). Os resultados desta caracterização estão apresentados na TABELA 5.1.

Tabela 5-1 Caracterização do hidrolisado hemicelulósico do bagaço de cana-deaçúcar bruto e tratado

\begin{tabular}{lcc}
\hline \multicolumn{1}{c}{ Composto } & Bruto $\left(\mathrm{g} . \mathrm{I}^{-1}\right)$ & Tratado $^{\left(\mathrm{g} . \mathrm{I}^{-1}\right)}$ \\
\hline Glicose & 2,7 & 2,2 \\
Xilose & 19,8 & 18,5 \\
Arabinose & 1,8 & 1,2 \\
Ácido Acético & 2,1 & 1,6 \\
Hidroximetilfurfural (HMF) & 0,05 & 0,002 \\
Furfural & 0,65 & 0,002 \\
\hline
\end{tabular}

Como pode ser observado na TABELA 5.1, as condições de hidrólise produziram um hidrolisado rico em xilose, demonstrando a extração seletiva da fração hemicelulósica do bagaço de cana-de-açúcar. A concentração de glicose

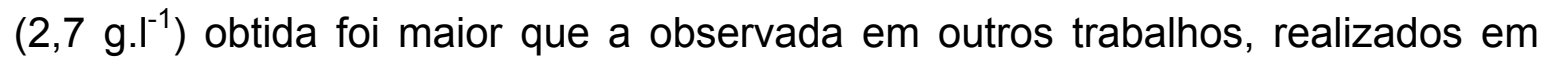
condições semelhantes de hidrólise, como em Cunha (2006) (1,3 g. -1 $^{-1}$ e Carvalho (2000) (1,66 g.L $\left.{ }^{-1}\right)$. Esta diferença pode ser atribuída às diferentes origens do bagaço de cana-de-açúcar utilizado em cada estudo. A concentração de xilose obtida encontra-se na média dos valores observados na literatura. 
Após a etapa de tratamento, foi observada uma diminuição na concentração dos inibidores como esperado, resultando em uma redução nas concentrações de furfural (96 \%), hidróximetilfurfural (99 \%) e de ácido acético (23 \%). Estes resultados evidenciam a eficiência do processo de tratamento, apesar de se ter observado diminuição na concentração dos açúcares de, em média, 20 $\%$. Este fato está associado principalmente à primeira etapa do tratamento (elevação do $\mathrm{pH}$ com $\mathrm{CaO}$ ) no qual é formado um precipitado espesso acima da membrana que provavelmente adsorve parte dos açúcares. Estas perdas podem ser atribuídas pela ocorrência de arrastes destes compostos durante o tratamento do hidrolisado, uma vez que neste processo há intensa variação de $\mathrm{pH}$ e formação de precipitados, os quais são removidos por filtração (CUNHA, 2006). Após o preparo, tratamento e caracterização do hidrolisado de bagaço de canade-açúcar foram realizados testes de condições iniciais de aeração, suplementação nutricional e parâmetros fermentativos $(\mathrm{pH}$, temperatura e concentração de inóculo) em meio contendo o hidrolisado tratado.

\subsection{Fermentação}

\subsubsection{Condições de aeração}

Em uma primeira etapa, foi avaliada o efeito da aeração na produção de etanol pelo micro-organismo em estudo. Em alguns casos, a anaerobiose pode causar um desvio metabólico para regeneração de cofatores importantes e diminuindo a conversão da xilose para etanol, sendo que o produto final da regeneração de cofatores é xilitol, causando uma diminuição na produção final de etanol (du PREEZ,1994).

Os resultados destes experimentos podem ser observados nas tabela 5.2, assim como os dados estatísticos (tabela 5.3) e o diagrama de Pareto (Figura 5.1) que ilustra o efeito dos fatores assim como a interação entre os mesmos. 

HM19.1.

Tabela 5-2 Avaliação da aeração na fermentação de xilose e glicose para etanol utilizando a levedura Spathaspora arborariae UFMG

\begin{tabular}{|c|c|c|c|c|c|c|c|c|c|c|c|}
\hline Experimento & $\begin{array}{l}\text { Agitação } \\
\text { (rpm) }\end{array}$ & $\begin{array}{l}\text { Vol. } \\
\text { de } \\
\text { Meio } \\
\text { (I) } \\
\end{array}$ & $\begin{array}{l}\text { Vol. do } \\
\text { Frasco(I) }\end{array}$ & $\begin{array}{l}\text { Celulas } \\
\left(g . I^{-1}\right)\end{array}$ & $\begin{array}{l}\text { Xilose } \\
\text { residual } \\
\left(g . I^{-1}\right)\end{array}$ & $\begin{array}{l}\text { Glicose } \\
\text { residual } \\
\left(\mathrm{g} . \mathrm{I}^{-1}\right)\end{array}$ & $\begin{array}{l}\text { Etanol } \\
\left(g . I^{-1}\right)\end{array}$ & $\begin{array}{l}\text { Fator de } \\
\text { Conversão. }\end{array}$ & $\begin{array}{l}\text { Consumo } \\
\text { de Xilose } \\
(\%)\end{array}$ & $\begin{array}{l}\text { Eficiência } \\
\text { (\%) }\end{array}$ & $\begin{array}{l}\text { Produtividade } \\
\left(g . I^{-1} \cdot h^{-1}\right)\end{array}$ \\
\hline 1 & 100 & 25 & 125 & 2,23 & 16,76 & 0,39 & 3,12 & 0,18 & 50,49 & 35 & 0,05 \\
\hline 2 & 200 & 25 & 125 & 2,35 & 18,09 & 0,29 & 0,42 & 0,02 & 47,50 & 4 & 0,01 \\
\hline 3 & 100 & 50 & 125 & 3,42 & 15,38 & 0,34 & 4,57 & 0,26 & 52,85 & 51 & 0,08 \\
\hline 4 & 200 & 50 & 125 & 2,43 & 16,47 & 0,52 & 0,48 & 0,03 & 51,38 & 5 & 0,01 \\
\hline 5 & 100 & 25 & 250 & 3,00 & 17,22 & 0,37 & 0,26 & 0,01 & 49,64 & 3 & 0,01 \\
\hline 6 & 200 & 25 & 250 & 2,27 & 18,37 & 0,36 & 1,48 & 0,09 & 46,50 & 18 & 0,02 \\
\hline 7 & 100 & 50 & 250 & 3,46 & 16,96 & 0,28 & 0,82 & 0,04 & 49,82 & 9 & 0,01 \\
\hline 8 & 200 & 50 & 250 & 3,60 & 15,96 & 0,29 & 0,43 & 0,02 & 55,27 & 3 & 0,01 \\
\hline
\end{tabular}

Tabela 5-3 Análise de Variância para Etanol dos parâmetros utilizados no experimento de aeração

\begin{tabular}{|c|c|c|c|c|c|}
\hline Fonte & Soma dos Quadrados & $g l$ & Média Quadrada & Razão-F & P-Valor \\
\hline A:Vol Hidrol & 4,4402 & 1 & 4,4402 & 733,92 & 0,0235 \\
\hline B:Agitação & 0,13005 & 1 & 0,13005 & 21,50 & 0,1352 \\
\hline C:Vol Fras & 3,92 & 1 & 3,92 & 647,93 & 0,0250 \\
\hline$A B$ & 1,125 & 1 & 1,125 & 185,95 & 0,0466 \\
\hline$A C$ & 7,25805 & 1 & 7,25805 & 1199,68 & 0,0184 \\
\hline $\mathrm{BC}$ & 0,5 & 1 & 0,5 & 82,64 & 0,0697 \\
\hline Erro Total & 0,00605 & 1 & 0,00605 & & \\
\hline Total (corr.) & 17,3794 & 7 & & & \\
\hline $\mathrm{R}^{2}$ & 99,9652 & & & & \\
\hline $\mathrm{R}^{2}$ (ajust. g.I) & 99,7563 & & & & \\
\hline Erro media absoluta & 0,07778 & & & & \\
\hline Erro padrão & 0,0275 & & & & \\
\hline
\end{tabular}


Os dados demonstram que a proporção utilizada na maioria dos experimentos em frascos Erlenmeyer, correspondente a proporção de 1:5 de frasco é uma opção a ser mantida, em detrimento as demais analizadas neste experimento, para garantir a aeração necessária (Figura 5.1). A intereação entre os volumes de frasco e o volume de meio de fermentação, representado pela interação $A C$ na figura 5.1 , demonstra que a produção de etanol será significativamente maior se mantida a proporção 1:5, corroborando a análise de variância (ANOVA). Não ocorreu diferença significativa nos níveis testados para o efeito aditação, sendo escolhido para os demais delineamentos experimentais o maior nível de agitação, com o objetivo de garantir uma aeração adequada para a fermentação, visto que a maioria das leveduras possui a necessidade de oxigênio para uma produção mais eficiente de etanol (NIGAM 2001a, 2001b, 2001c). aeração

Figura 5-1 Diagrama de Pareto com os fatores utilizados nos experimentos de

Nas condiçõoes utilizadas no presente trabalho não houve produção de xilitol pela levedura, indicando que as condições utilizadas não acarretou em uma condição de anaerobiose, o que causaria a regeneração de cofatores e a formação de xilitol (du PREEZ,1994).

\subsubsection{Suplementação nutricional}


A suplementação do meio de fermentação é muito importante uma vez que prolonga a viabilidade das leveduras na fermentação (KOTARSKA et al., 2006) Os microorganismos retiram do meio ambiente todas as substâncias necessárias para a síntese celular e para obtenção de energia, variando de acordo com as cepas. Na fermentação para etanol, além das fontes de carbono, os organismos necessitam de outros cofatores e compostos para a manutenção do maquinário metabólico que, caso não seja devidamente renovado, pode ocorrer na morte celular e consequente diminuição na produção de etanol.

De acordo com os dados obtidos (Tabela 5.4 e 5.5), a melhor conversão em etanol apresentada foi aquela utilizando extrato de levedura em sua concentração mais alta $\left(1,0 \mathrm{~g} \cdot \mathrm{L}^{-1}\right)$, sem a presença de outros nutrientes usados no planejamento experimental, como o sulfato de magnésio $\left(\mathrm{MgSO}_{4}\right)$ e o sulfato de amônio $\left(\mathrm{NH}_{4} \mathrm{SO}_{4}\right)$. Pode se inferir que, devido a composição complexa do extrato de levedura, extraída de $S$. cerevisiae, possuindo diversos nutrientes nitrogenados, importantes para o crescimento celular e manutenção do maquinário metabólico, assim como vitaminas, que auxiliam o metabolismo de produção do etanol e o crescimento celular, ambos desejados nas etapas fermentativas e de preparo de inóculo, respectivamente (INGLEDEW, CASEY, MAGNUS,1984).

Embora não tenha sido relevante para o presente estudo (Figura 5.18), o magnésio tem uma boa participação na produção de etanol por leveduras, tais como Scheffersomyces stiptis (SLININGER, 2006), Candida tropicalis (LOHMEIER-VOGEL, 1995), Candida shehatae (XIA, 1995). Geralmente esse nutriente é utilizado no preparo do de inóculo ou na fermentação, de modo a aumentar o fator de rendimento de produção $\left(Y_{p / s}\right)$. No caso desta fermentação, o fator de rendimento foi inferior ao obtido por outras leveduras $\left(Y_{p / s}=0,26\right)$. Esse resultado pode ser explicado por uma não exploração, no experimento, de outras variáveis presentes no processo tais como o pH, composição de açúcares no meio, temperatura, e concentração de células na fermentação, verificados em outra etapa do experimento.

Compostos nitrogenados, tais como a amônia e a uréia, são amplamente utilizado em meios complexos para fermentação, sendo que o existem alguns 
estudos destacando a utilização de uréia para algumas leveduras, como Scheffersomyces stiptis (FERREIRA, 2011) e Candida guilermondii, para produção de etanol (SARROUH, 2009) e xilitol, respectivamente. Apesar de ser um nutriente importante em outros organismos durante a fermentação, a uréia não foi escolhida para a experimentação devido a incapacidade da levedura em converter essa substância para ser utilizada no anabolismo de aminoácidos (CADETE, 2009). Devido a essa incapacidade, para avaliação da suplementação de nutrientes nitrogenados nestes experimentos, foi utilizado sulfato de amônio que, apesar de ser metabolicamente utilizável pela levedura, não causou efeitos estatisticamente significantes na fermentação a longo prazo.. 
Tabela 5-4 Avaliação da suplementação nutricional na fermentação de xilose e glicose para etanol utilizando a levedura Spathaspora arborariae UFMG-HM19.1.

\begin{tabular}{|c|c|c|c|c|c|c|c|c|c|c|c|}
\hline Experimento & $\begin{array}{l}\mathrm{Mg} \\
\left(\mathrm{g} . \mathrm{I}^{-}\right.\end{array}$ & $\begin{array}{l}\mathrm{NH}_{4} \\
\left(\mathrm{~g} . \mathrm{I}^{\prime}\right. \\
\mathrm{P}^{\prime}\end{array}$ & $\begin{array}{l}\text { Extrato } \\
\text { de } \\
\text { Levedura. } \\
\left(\mathrm{g} . \mathrm{I}^{-1}\right) \\
\end{array}$ & $\begin{array}{l}\text { Concentração } \\
\text { Celular Final } \\
\left(\left.g^{-1}\right|^{-1}\right)\end{array}$ & $\begin{array}{l}\text { Xilose } \\
\text { Residual } \\
\left(\mathbf{g} . \mathbf{I}^{-1}\right)\end{array}$ & $\begin{array}{l}\text { Glicose } \\
\text { Residual } \\
\left(\mathbf{g} . \mathbf{I}^{-1}\right)\end{array}$ & $\begin{array}{l}\text { Etanol } \\
\left(g . I^{-1}\right)\end{array}$ & $\begin{array}{l}\text { Fator de } \\
\text { Conversão. }\end{array}$ & $\begin{array}{l}\text { Consumo } \\
\text { de Xilose } \\
(\%)\end{array}$ & $\begin{array}{l}\text { Eficiência } \\
(\%)\end{array}$ & $\begin{array}{l}\text { Produtividade } \\
\left(g^{-1} I^{-1} \cdot h^{-1}\right)\end{array}$ \\
\hline 1 & 0 & 0 & 0 & 3,47 & 29,42 & 2,55 & 0,47 & 0,17 & 7,66 & 0,34 & 0,01 \\
\hline 2 & 5 & 0 & 0 & 3,42 & 22,40 & 2,26 & 1,21 & 0,10 & 30,19 & 0,20 & 0,01 \\
\hline 3 & 0 & 5 & 0 & 3,33 & 10,23 & 0,34 & 0,71 & 0,02 & 69,65 & 0,05 & 0,01 \\
\hline 4 & 5 & 5 & 0 & 3,52 & 21,28 & 0,36 & 0,79 & 0,05 & 34,34 & 0,11 & 0,01 \\
\hline 5 & 0 & 0 & 5 & 3,41 & 15,30 & 0,29 & 4,77 & 0,26 & 53,26 & 0,51 & 0,07 \\
\hline 6 & 5 & 0 & 5 & 3,67 & 16,00 & 0,28 & 3,06 & 0,15 & 54,83 & 0,30 & 0,05 \\
\hline 7 & 0 & 5 & 5 & 3,46 & 16,96 & 0,28 & 0,82 & 0,04 & 49,82 & 0,08 & 0,01 \\
\hline 8 & 5 & 5 & 5 & 3,30 & 15,96 & 0,29 & 1,43 & 0,07 & 55,27 & 0,13 & 0,02 \\
\hline
\end{tabular}

Tabela 5-5 Análise de Variância para Etanol dos parâmetros utilizados no experimento de aeração

\begin{tabular}{|c|c|c|c|c|c|}
\hline Fonte & Soma dos Quadrados & $g l$ & Média Quadrada & Razão-F & P-Valor \\
\hline A:Magnésio & 0,0432744 & 1 & 0,0432744 & 0,15 & 0,7091 \\
\hline B:Amônia & 8,36207 & 1 & 8,36207 & 28,89 & 0,0007 \\
\hline C:Extrato & 11,9593 & 1 & 11,9593 & 41,32 & 0,0002 \\
\hline$A B$ & 0,740073 & 1 & 0,740073 & 2,56 & 0,1485 \\
\hline$A C$ & 0,991568 & 1 & 0,991568 & 3,43 & 0,1013 \\
\hline $\mathrm{BC}$ & 7,3738 & 1 & 7,3738 & 25,48 & 0,0010 \\
\hline Erro Total & 2,31524 & 8 & 0,289405 & & \\
\hline Total (corr.) & 31,7854 & 15 & & & \\
\hline $\mathrm{R}^{2}$ & 92,716 & & & & \\
\hline $\mathrm{R}^{2}$ (ajust. g.I) & 86,3425 & & & & \\
\hline Erro media absoluta & 0,537964 & & & & \\
\hline Erro padrão & 0,379731 & & & & \\
\hline
\end{tabular}


Figura 5-2 Diagrama de Pareto com os nutrientes utilizados nos experimentos de suplementação para produção de etanol

Com base nos dados estatísticos e no diagrama de Pareto obtidos nos dados observados nessa nessa etapa, foi determinado que a suplementação do meio de cultivo fosse realizada com adição de extrato de levedura, devido a seu efeito significativo para a produção de etanol na concentração máxima do experimento, utilizando-se como parâmetro de escolha o fator de rendimento obtido nesse experimento e os P-valores da análise de variancia (ANOVA). A segunda etapa dos experimentos delineados nesse trabalho foi realizada, de modo a escolher o melhor conjunto de fatores, de modo a torna-lo mais eficiente para viabilizar uma futura aplicação biotecnológica da levedura em estudo.

\subsubsection{Parâmetros fermentativos}

De modo a melhorar o bioprocesso produtivo de etanol, muitos trabalhos foram realizados para determinar as melhores condições para a fermentação de pentoses a etanol (OLSEN, HANH-HAGERDAL ,1996). Esses estudos mostram que a concentração celular do inóculo, a temperatura e o pH são fatores importantes para uma conversão mais eficiente dos açucares pela levedura. 
O consumo total de glicose foi observado nos meios de cultivo com menor concentração de inóculo e pH inicial 4 e 6, quando cultivados a $40^{\circ} \mathrm{C}$. Nos cultivos realizados com a presença de maior concentração celular, apenas as fermentações em $\mathrm{pH}$ inicial 6 a $30^{\circ} \mathrm{C}$ não tiveram o consumo total deste monosacarídeo.

Através de análise estatística, foi obtida a Equação 5.1 , onde pode-se observar a participação significativa de todos os fatores amostrados.

Etanol $=5,40075+1,79925^{*} \mathrm{~T}-0,7025^{*} \mathrm{P}-1,80975^{*} \mathrm{C}+0,0985^{*} \mathrm{~T}^{\star} \mathrm{P}+0,3565^{*} \mathrm{~T}^{*} \mathrm{C}-0,11775^{*} \mathrm{P}^{*} \mathrm{C} \quad$ (Eq 5.1)

Onde:

Etanol= concentração de Etanol $\left(g \cdot I^{-1}\right)$

T= Temperatura (valor codificado)

$\mathrm{P}=\mathrm{pH}$ (valor codificado)

$\mathrm{C}=$ Concentração de inóculo (valor codificado

Em nenhum ensaio foi observado o consumo completo da xilose disponível no meio, a qua foi lentamente consumida na maioria das fermentações, apresentando o maior consumo $(67,8 \%)$ em pH inicial 6 e temperatura de $30^{\circ} \mathrm{C}$.

Todas as fermentações resultaram na produção de etanol, com diferentes concentrações (Tabela 5.6). As melhores condições de produção de etanol foram em $\mathrm{pH}$ inicial 4 e temperatura $40^{\circ} \mathrm{C}\left(\mathrm{Y}_{\mathrm{p} / \mathrm{s}}=0,50\right), \mathrm{pH}$ inicial 4 e temperatura $30^{\circ} \mathrm{C}$ $\left(\mathrm{Y}_{\mathrm{p} / \mathrm{s}}=0,47\right)$ e $\mathrm{pH}$ inicial 6 e temperatura $40^{\circ} \mathrm{C}\left(\mathrm{Y}_{\mathrm{p} / \mathrm{s}}=0,41\right)$. Esse resultado é satisfatório, considerando alguns trabalhos utilizando leveduras conversoras de xilose, tais como Scheffersomyces stipitis DSM 365 em hidrolisado ácido de canade-açúcar não tratado $\left(Y_{\mathrm{p} / \mathrm{s}}=0,30\right)$ (CANILHA et. al., 2010) ou hidrolisado de fruto de palma por Mucor indicus $\left(Y_{p / s}=0,45\right)$ (MILLATI, 2011), demonstrando que a levedura do presente trabalho tem uma fator de rendimento superior a outros organismos da literatura consultada, estando muito próximo ao rendimento teórico 
em frascos de Erlenmeyer, tornando-se interessante para estudos em reatores para aumento de escala.

O comportamento de consumo de glicose foi diferente de outras espécies fermentadoras, como Scheffersomyces stiptis em hidrolisado de bagaço de cana (CANILHA et. al, 2010), Candida tropicalis em hidrolisado de podas de oliveira (MARTIN et. al., 2010), mas aceitável dentro de seu gênero (Spathaspora). Long e colaboradores (2010) utilizaram a levedura S. passalidarum, para a produção de etanol sob uma temperatura de $42^{\circ} \mathrm{C}$, condição similar a utilizada no presente trabalho. Em todos os trabalhos citados anteriormente, observou-se um maior consumo de glicose em detrimento do consumo de xilose, corroborando também com trabalhos específicos sobre consumo de xilose (AGBOGBO et. al., 2006), demonstrando que a fermentação de xilose está adequada com o observado em outras fermentações.

O consumo de xilose nos organimos capazes de fermentar esse açúcar é notoriamente lento quando utilizados hidrolisados de materiais lignocelulósicos. As fermentações desses materiais demoram longos períodos para ocorrer o consumo completo da xilose presente no meio, alcançando até $240 \mathrm{~h}$ de fermentação (MARTIN et. al., 2010). Este longo período de fermentação pode ser explicado tanto pela baixa concentração celular incial quanto por inibidores presentes no hidrolisado hemicelulóstico.

A baixa concentração celular pode indicar que os organismos fermentadores de xilose não fermentam na mesma taxa que $S$. cerevisiae fermenta glicose, necessitando de muito mais tempo para converter o substrato a etanol. Altas concentrações celulares poderiam levar, proporcionalmente, a uma baixa disponiabilidade de açúcares para a alta proporção de organismos, diminuindo a produção de etanol. A levedura Spathaspora arborariae UFMGHM19.1.1 em meios sintéticos e em altas concentrações celulares $\left(10 \mathrm{~g} \cdot \mathrm{L}^{-1}\right)$ foi capaz de consumir completamente os açúcares contidos em meio sintético (20g.L' ${ }^{1}$ de xilose) em 48h de fermentação (CADETE, 2009).

O tempo da fermentação pode ser explicado pela presença de inibidores metabólicos, tanto o ácido acético quanto compostos fenólicos como o furfural e o 
hidroxi-metil-furfural (HMF). O efeito tóxico do ácido acético, presente em $\mathrm{pH}$ baixo, não foi observado tão acentuadamente nas fermentações experimentais, sendo que um dos crescimentos ideais foi durante o pH baixo, algo inusitado para uma fermentação em hidrolisado hemicelulósico. Durante a hidrólise ocorre a formação de ácidos acéticos derivados dos radicais acéticos presentes na porção hemicelulósica. Durante o processo de tratamento do hidrolisado para a fermentação, ocorre a redução da concentração de ácido acético devido a evaporação no processo de concentração do hidrolisado. Em outras fermentações com o organismo ocorreu inibição por ácido acético em pH de 4,75 (constante de dissociação do ácido acético), assim como outros organismos fermentadores, como Candida shehatae, Scheffersomyces stiptis, Candida tropicalis em bagaço de cana, com a presença de ácido acético em concentrações variadas. O efeito do ácido acético nas células fermentadoras ocorre devido a alteração eletrolítica no citosol das leveduras, causando um estresse metabólico, diminuindo a produção de etanol. 
Tabela 5-6 Avaliação dos parâmetros fermentativos na conversão de xilose e glicose para etanol utilizando a levedura Spathaspora arborariae UFMG-HM19.1

\begin{tabular}{|c|c|c|c|c|c|c|c|c|c|c|c|}
\hline Experimento. & $\begin{array}{l}\text { Temperatura. } \\
{ }^{\circ} \mathrm{C}\end{array}$ & $\mathrm{pH}$ & $\begin{array}{l}\text { Concentração. } \\
\text { Inóculo }\end{array}$ & $\begin{array}{l}\text { Concen. } \\
\text { Celular } \\
\text { Final } \\
\left(\text { g. }\left.\right|^{-1}\right)\end{array}$ & $\begin{array}{l}\text { Xilose } \\
\text { Residual } \\
\left(\mathbf{g} . \mathbf{l}^{-1}\right)\end{array}$ & $\begin{array}{l}\text { Glicose } \\
\text { Residual } \\
\left(\mathbf{g} . \mathrm{I}^{-1}\right)\end{array}$ & $\begin{array}{l}\text { Etanol } \\
\left(g . I^{-1}\right)\end{array}$ & $\begin{array}{l}\text { Fator de } \\
\text { Conversão. }\end{array}$ & $\begin{array}{l}\text { Consumo } \\
\text { de Xilose } \\
\text { (\%) }\end{array}$ & $\begin{array}{l}\text { Eficiência } \\
\text { (\%) }\end{array}$ & $\begin{array}{l}\text { Produtividade } \\
\left(g \cdot I^{-1} \cdot h^{-1}\right)\end{array}$ \\
\hline 1 & 30 & 4 & 0,5 & 3,49 & 18,89 & 0,49 & 6,89 & 0,47 & 34,70 & 0,93 & 0,11 \\
\hline 2 & 40 & 4 & 0,5 & 1,19 & 17,35 & 0 & 8,71 & 0,50 & 41,58 & 0,98 & 0,14 \\
\hline 3 & 30 & 6 & 0,5 & 2,23 & 10,04 & 1,95 & 4,52 & 0,18 & 67,83 & 0,36 & 0,07 \\
\hline 4 & 40 & 6 & 0,5 & 1,21 & 13,17 & 0 & 8,76 & 0,41 & 54,61 & 0,81 & 0,14 \\
\hline 5 & 30 & 4 & 1 & 3,48 & 15,83 & 0 & 1,82 & 0,09 & 45,28 & 0,19 & 0,03 \\
\hline 6 & 40 & 4 & 1 & 1,36 & 16,9 & 0 & 7,04 & 0,37 & 44,26 & 0,74 & 0,11 \\
\hline 7 & 30 & 6 & 1 & 3,14 & 18,06 & 0,55 & 1,01 & 0,06 & 41,92 & 0,12 & 0,01 \\
\hline 8 & 40 & 6 & 1 & 1,35 & 16,93 & 0 & 4,55 & 0,24 & 43,30 & 0,48 & 0,07 \\
\hline
\end{tabular}

Tabela 5-7 Análise de Variância para Etanol dos parâmetros utilizados no experimento dos parâmetros fermentativos

\begin{tabular}{|c|c|c|c|c|c|}
\hline Fonte & Soma dos Quadrados & $g l$ & Média Quadrada & Razão-F & P-Valor \\
\hline A:Temperatura & 51,7968 & 1 & 51,7968 & 97,92 & 0,0000 \\
\hline $\mathrm{B}: \mathrm{pH}$ & 7,8961 & 1 & 7,8961 & 14,93 & 0,0048 \\
\hline C:Inóculo & 52,4031 & 1 & 52,4031 & 99,07 & 0,0000 \\
\hline$A B$ & 0,155236 & 1 & 0,155236 & 0,29 & 0,6028 \\
\hline$A C$ & 2,03348 & 1 & 2,03348 & 3,84 & 0,0856 \\
\hline $\mathrm{BC}$ & 0,221841 & 1 & 0,221841 & 0,42 & 0,5354 \\
\hline Total error & 4,23175 & 8 & 0,528969 & & \\
\hline Total (corr.) & 118,744 & 15 & & & \\
\hline $\mathrm{R}^{2}$ & 96,4362 & & & & \\
\hline $\mathrm{R}^{2}$ (ajust. g.I) & 93,3179 & & & & \\
\hline Erro media absoluta & 0,727303 & & & & \\
\hline Erro padrão & 0,511 & & & & \\
\hline
\end{tabular}



interações

Figura 5-3 Diagrama de Pareto das parâmetros fermentativos experimentais e suas

Assim como o ácido acético é formado pelo processo de hidrólise ácida, também é nesse processo que se formam o furfural e o hidroxi-metil-furfural formados a partir de, respectivamente, xilose e glicose, ambos presentes nos materiais lignocelulósicos. Tais inibidores metabólicos podem ser reduzidos por tratamentos pré-fermentantação, como liming e overliming, por exemplo, ainda que não possam totalmente eliminar os compostos metabólicos, diminuem consideravelmente sua presença no hidrolisado. Assim, a inibição, ainda que presente permite uma fermentação, ainda que necessite de maior tempo para processar completamente os açúcares presentes no hidrolisado capazes de serem metabolizados pela levedura. O organismo mostrou-se inibido nas condições amostradas, corroborando com Cunha-Pereira e colaboradores (2011), que mostraram que durante o período os inibidores teriam efeitos sobre a fermentadora, apesar de serem consumidos após um determinado período de tempo em baixas concentrações. Outras leveduras também tem a capacidade de se alimentar de tais compostos fenólicos, como Issatchenkia occidentalis (redução de $85 \%$ de HMF e $62 \%$ furfural) (FONSECA, 2011).

Considerando os fatores utilizados nesse experimento, as análises estatísticas e o Diagrama de Pareto, pode-se observar que as melhores condições para a produção de etanol são a concentração de inóculo de 0,5 g.l ${ }^{-1}$, a 
temperatura de $40^{\circ} \mathrm{C}$ e $\mathrm{o} \mathrm{pH} 4$, não sendo observado estatisticamente uma interação significativa entre esses fatores nos níveis sugeridos, ainda que a temperatura e o $\mathrm{pH}$ possuam interação (Tabela 5-7), ela não foi significativa para a produção de etanol (Figura 5-3). 


\section{CONCLUSÕES}

Os resultados obtidos permitem concluir que

- A levedura Spathaspora arborariae UFMG-HM19.1 foi capaz de produzir etanol em hidrolisado de cana-de-açúcar sendo que, nas condições avaliadas, as maiores concentrações obtidas foram em meios potencialmente estressantes para leveduras em hidrolisado.

- Houve a necessidade de suplementação do hidrolisado, sendo o extrato de levedura o nutriente mais significativamente importante para a produção de etanol utilizando a levedura Spathaspora arborariae UFMG-HM19.1

- A fermentação utilizando a levedura Spathaspora arborariae UFMGHM19.1 obteve um fator de rendimento muito próximo ao teórico utilizando como parâmetros fermentativos a temperatura de $40^{\circ} \mathrm{C}, \mathrm{o} \mathrm{pH} 4$ e uma concentração inicial de inóculo de $0,5 \mathrm{~g} . \mathrm{I}^{-1}$

- Os fatores significativos observados neste trabalho, do ponto de vista estatístico, são isolados, ou seja, não possuem interações significativas para a produçao de etanol. 


\section{REFERÊNCIAS}

ADLER, E. Lignin chemistry: past, present and future. Wood Science Technology, v. 11, p. 169-218, 1977.

AGBOGBO, F. K., COWARD-KELLY, G., TORRY-SMITH, M. and Kevin S. WENGER, K. S. Fermentation of glucose/xylose mixtures using Pichia stipitis Process Biochemistry. Volume 41, Issue 11, November 2006, Pages 2333-2336.

ALEXANDER, M. Biodegradation and bioremediation. Academic Press, San Diego,California, 302 p. 1994.

ALFENORE S, MOLINA-JOUVE C, GUILLOUET SE, URIBELARREA JL, GOMA G, BENBADIS L.; Improving ethanol production and viability of Saccharomyces cerevisiae by a vitamin feeding strategy during fed-batch process. Applied Microbiology and Biotechnologyl;60:67- 72. 2002.

ALVES, L. A. Avaliação do tratamento do hidrolisado hemicelulósico de bagaço de cana-de-açúcar para produção biotecnológica de xilitol. 1997. 92p. Dissertação (Mestrado em Biotecnologia Industrial) Faculdade de Engenharia Química de Lorena, Lorena, 1997.

ANSELMO FILHO, P.; BADR, O. Biomass resources for energy in North-Eastern Brazil. Applied Energy, v. 77, p. 51-67, 2004.

BETANCUR, G. J. V. Avanços em biotecnologia de hemicelulose para produção de etanol por Picchia stipitis.. 123 f. Tese (Mestrado em Tecnologia de Processos Químicos e Bioquímicos). Escola de Química,Universidade Federal do Rio de Janeiro, Rio de Janeiro 2005.

BIRCH RM, WALKER GM. Influence of magnesium ions on heat shock and ethanol stress responses of Saccharomyces cerevisiae. Enzyme and Microbial Technology 26:678-87, 2000.

BRUINENGBERG, P.M.; DE-BOT, P.H.M.; VAN-DIJKEN, J.P.SCHEFFERS, W.A. $\mathrm{NADH}$-linked aldose redutase: the key to anaerobic alcoholic fermentation of xylose by yeast. Applied Microbiology and Biotechnology,v.19,p.256-60,1984. 
BUSTOS, G.; RAMIREZ, J. A.; GARROTE, G. and VÁSQUEZ' M. Modeling of the hydrolysis of sugar cane bagasse with hydrochloric acid Applied Biochemistry and Biotechnology v. 104, n. 1 / January, 2003 pp.51-68.

CADETE R.M. , SANTOS, R. O. , MELO M.A. , MOURO A. , GONSALVES D. L. , STAMBUK B. U., GOMES F. C. O. , LACHENCE M. A.\& ROSA C. A. Spathaspora arborariae sp. nov., a D-xylose-fermenting yeast species isolated from rotting wood in Brazil FEMS Yeast Research v. 9 n. 8, p. 1338 - 1342, 2009

CANETTIERI, E. V.; ALMEIDA E SILVA,J. B.; FELIPE,M. G. A Obtenção Biotecnológica de Xilitol a parir de Cavacos de Eucalipto Revista Brasileira de ciências Farmacêuticas v.38,n.3, jul/set. 2002

CANILHA L.,CARVALHO, W., FELIPE, M. G. A. , ALMEIDA E SILVA J. B. e GIULLIETI, M. Ethanol Production from Sugarcane Bagasse Hydrolysate Using Pichia stipitis. Applied biochemistry and biotechnology. V. 161, n. 1-8, p. 8492, 2010.

CARMOUZE, J. P. O metabolismo dos ecossistemas aquáticos: fundamentos teóricos,métodos de estudos e análises químicas. São Paulo: Edgard Blücher: Fapesp. 254p.1994.

CONAB - Companhia Nacional de Abastecimento. Disponível em:< http://www.conab.gov.br/conabweb/index.php?PAG=73\&NSN=305>. Acesso em: nov. 2009.

CONAB - Companhia Nacional de Abastecimento. Disponível em: < http://www.conab.gov.br/OlalaCMS/uploads/arquivos/11_05_10_09_13_03_boleti m_cana_portugues_-_maio_-_2011_1o_lev..pdf> Acesso em: maio 2011

COSTA, F. Moagem: a Transformação da cana em riqueza. Disponível em:< http://www.revistarural.com.br/Edicoes/2005/artigos/rev86_moagem.htm>. Acesso em: Nov 2009.

CUNNHA-PEREIRA, F.; HHICKERT, L. R.; SEHNEM, N. T.; SOUZA-CRUZ, P. B.; ROSA, C. A.; and AYUB, M. A. Z. Conversion of sugars present in rice hull hydrolysates into ethanol by Spathaspora arborariae, Saccharomyces cerevisiae, 
and their co-fermentations. Bioresource Technology. v. 102, n. 5, March 2011, p. $4218-4225$.

DAVIS, L.; JEON, Y. J.; SVENSON, C.; ROGERS, P.; PEARCE, J.; PEIRIS, P. Evaluation of wheat stillage for ethanol production by recombinant Zymomonas mobilis. Biomass and Bioenergy, v. 29, p. 49-59, 2005.

DAWSON,L.;BOOPATHY,R.Cellulosic ethanol production from sugarcane bagasse without enzymatic saccharification.Bio Resources,v.3,n.2,p.452$460,2008$.

DOMBEK, K.M., INGRAM, L.O.,. Magnesium limitation and its role in apparent toxicity of ethanol during yeast fermentation. Applied and Environmental Microbiology. v.52, p.975-981, 1986.

DU PREEZ, J. C.; BOSCH, M.; PRIOR, B. A. Xylose fermentation by Candida shehatae and Pichia stipitis: effects of $\mathrm{pH}$, temperature and substrate concentration. Enzyme Microb. Technol., v. 8, p. 360-364, 1986.

DU PREEZ, J. C. Process parameters and environmental factors affecting Dxylose fermentation by yeasts. Enzyme Microb. Technol., v. 16, p. 944-952, 1994.

DUFF, S. J. B., MURRAY, W. D. Bioconversion of forest products industry waste cellulosics to fuel ethanol: a review. Bioresource Technology, v. 55, p. 1-33, 1996.

DUMSDAY, G.J.; JONES, K.; STANLEY, G.A.; PAMMENT, N.B. Recombinant organisms for ethanol production from hemicellulosic hydrolyzates - A Review of Recent Progress. Australasian Biotechnology, v. 7, n. 4, p. 285-295, 1997.

ELIASSON, A.; CHRISTENSSON, C.; WAHLBOM, F.; HAHN-HÄGERDAL, B. Anaerobic Xylose Fermentation by Recombinant Saccharomyces cerevisiae Carrying XYL1, XYL2, and XYS1 in Mineral Medium Chemostat Cultures. Applied and environmental Microbiology, v. 66, n. 8, p. 3381-3386, 2000.

ELOHMEIER-VOGEL ,E.M.; HAHN-HAGERDAL, B., VOGEL, H.J. Phosphorus-31 and carbon-13 nuclear magnetic resonance studies of glucose and xylose 
metabolism in Candida tropicalis cell suspensions. Appl.Environ. Microbiol. Vol. 61, n. 04, p. 1414-1419, 1995.

FENGEL, D.; WEGENER, G. Wood Chemistry, Ultrastructure, Reactions. Berlin: Walter de Gruyter, 1989, 613 p..

FERREIRA, ADRIANA D. ;MUSSATTO, S. I.; CADETE, R M. ; ROSA, C A. ; SILVA, S. S. . Ethanol production by a new pentose-fermenting yeast strain Scheffersomyces stipitis UFMG-IMH 43.2 isolated from Brazilian forest. Yeast (Chichester, England. Print), 2011.

FONSECA, B. G., MOUTTA, R. O., FERRAZ, F. O., VIEIRA, E. R., NOGUEIRA, A. N., BARATELLA, B. F., RODRIGUES, L. C., HOU-RUY, Z. and SILVA, S. S. ,Biological detoxification of different hemicellulosic hydrolysates using Issatchenkia occidentalis CCTCC M 206097 yeast Journal, of industrial microbiology \& biotechnology v. 38, n. 1, p. 199-207 2011.

FROLLINI, F.; PIMENTA, M. S. A. Lignin: Utilization as a macromonomer in the synthesis of phenolic type resins. Anais da Associação Brasileira de Química, v. 46, n. 1, p. 43-49, 1997.

FURUKAWA K, KITANO H, MIZOGUCHI H, HARA S. Effect of cellular inositol content on ethanol tolerance of Saccharomyces cerevisiae in sake brewing. Journal of Bioscience and Bioengineering; v.38, p.107-13, 2004.

GNANSOUNOU, E.; DAURIAT, A.; WYMAN, C, E. Refining sweet sorghum to ethanol and sugar: economic trade-offs in the context of North China. Bioresource Technology, v. 96, p.985-1002, 2005.

GOLDSTEIN, I. S. Organic chemicals from Biomass. 1981 Boca Raton: CRC Press, 1981, 309 p.

HAHN-HAGERDAL, B.; JEPPSSON, H.; SKOOG, K.; PRIOR, B. A. Biochemistry and physiology of xylose fermentation by yeasts. Enzyme Microbiology and technol, v. 16, p. 933-942, 1994.

HAMACHER, T.; BECKER, J.; GÁRDONYI, M.; HAHN-HÄGERDAL, B.; BOLES, E. Characterization of the xilose-transporting properties of yeast 
hexosetransporters and their influence on xylose utilization. Microbiology, v. 148, p. 2783-2788, 2002.

IEA-SP -Instituto de Economia Agrícola. In: Bioetanol de cana-de-açúcar energia para o Desenvolvimento Sustentável. Disponível em: <http://www.iea.sp.gov.br/out/bioenergia/textos/bio_06_2008.pdf> Acesso em mar. de 2010.

INGLEDEW, W. M.; CASEY, G.P.; MAGNUS, C.A High-Gravity Brewing: Effects of Nutrition on Yeast Composition, Fermentative Ability, and Alcohol Production Appl Environ Microbiol. v.48 n.3, p. 639-646 1984.

JANSEN, N.B.;FLICKINGER, M.C.; TSAO, G.T. production of 2,3-butanediol from d-xylose by Klebsiella oxytoca ATCC8724 Biotechnology and Bioengineering,v.26,n.4,p.362-369,2004.

JEFFRIES, T. W. Utilization of xilose by bacteria, yeast and fungi. Advances in Biochemical Engineering, v. 27, p. 1-32, 1983.

JIN, Y. S.; LAPLAZA, J. M.; JEFFRIES, T. W. Saccharomyces cerevisiae engineered for xylose metabolism exhibits a respiratory response. Applied and Environmental Microbiology, v. 70, p. 6816-6825, 2004.

KASTNER, J.R., ROBERTS, R.S., JONES, W.J. Effect of pH on cell viability and product yields in D-xylose fermentations by. Candida shehatae. Applied Microbiology and Biotechnology , v.45, p.224 228, 1996.

KOTARSKA K, CZUPRINSK' SKI B, KLOSOWISKli G. Effect of various activators on the course of alcoholic fermentation. Journal Food Eng;77:965-71. 2006.

KUHAD, R.C.; SING, A. Lignocellulose biotechnology: Current and future prospects. Critical Reviews in Biotechnology, v. 13, n. 2, p. 151-172, 1993.

KUMAR,P.BARRET,D.M.;DELWICHE,M.J.;STROEVE,P.Methods for Pretretament of Lignocellulosic Biomass for Efficient Hydrolysis and Biofuel Production Industrial Engineering Chemical Resource,v.48,p.3713-3729,2009.

LAPLACE J. M.; DELGeneS, J. P.; MOLETTA R.; NAVARRO, J. M. Simultanoeus alcoholic fermentation of D-xylose and D-glucose by four selected 
microbial strains: process considerations in relation with ethanol tolerance. Biotechnology Letters, v. 13, p. 445-450, 1991.

LASER, M.; SCHULMAN, D.; ALLEN, S. G.; LICHWA, J.; ANTAL Jr., M. J.; LYND, L. R. A comparison of liquid hot water and steam pretreatment of sugarcane bagasse for bioconversion to ethanol. Bioresource Technology, v. 81, p. 33-44, 2002.

LATIF, F.; RAJOCA,M.I. production of ethanol and xilitol from corn cobs by yeast. Bioresourse Technology, v.77,p.57-63,2001.

LAVARACK, B. P.; GRIFFIN, G. J.; RODMAN, D. The acid hydrolysis of sugarcane bagasse hemicellulose to produce xilose, arabinose, glucose and other products. Biomass and Bioenergy, v. 23, p. 367-380, 2002.

LEÃO, C.; Van UDEN N. Effects of ethanol and other alcohols on the glucose transport system of Saccharomyces cerevisiae. Biotechnology Letters, v. 4, p. 721-724, 1982.

LIN, Y; TANAKA S.; Ethanol fermentation from biomass resources: current state and prospects., Applied Microbiology Biotechnology, v. 69, p. 627-642, 2006.

LOHMEIER-VOGEL, E.M.; SOPHER, C.R.; LEE, H. Intracellular acidification as a mechanism for inhibition by acid hydrolysis-derived inhibitors of xylose fermentation by yeasts. Journal of Industrial Microbiology and Biotechnology, v.20, p.75-81, 1998.

MAIA, A.B.R.A.Fundamentos de Fermentação Alcoolica Belo Horizonte: UFMG ,1989 Apostila do curso de engenharia Química .

MARTIN, J. F. G., CUEVAS, M., BRAVO, V., and SÁNCHEZ, S. Ethanol production from olive prunings by autohydrolysis and fermentation with Candida tropicalis. Renewable Energy. V. 35, n. 7, July 2010, p. 1602-1608.

MAYALAGU S., PATTURAJAN M. and CHSTTERJI D.' The presence of two tightly bound $\mathrm{Zn}^{2+}$ ions is essential for the structural and functional integrity of yeast RNA polymerase II Gene v. 190, n. 1, 1997, p. 77-85. 
McMILLAN, J.D. Pretreatment of Biomass. American Chemical SocietySymposium. v. 566, p.292-324, 1994.

METCALF \& EDDY. Wastewater engineering: treatment, disposal and reuse. $3^{\text {rd }}$ ed. Metclaf \&Eddy, Inc. 1991 p. 1334.

MEYRIAL, V.; DELGENES, J. P.; DAVISON, J.; SALMON, J. M.; MOLETTA, R.; GOUNOT, A. M. Relationship between effect of ethanol on proton flux across plasma membrane and ethanol tolerance, in Pichia stipitis. Anaerobe, v. 3, 423429, 1997.

MILLATI, R.; EDEBO, L.; TAHERZADEH, M. J. Performance of Rhizomucor, Mucor in ethanol production from glucose, xilose, and wood hydrolyzates.Enzime and Microbial Technology, 2004.

MILLATI,R.; WIKANDARI, R., TRIHANDAYANI, E.T.; CAHYANTO, M.N.; TAHERZADEH, M.J.; NIKLASSON, C.; Ethanol from Oil Palm Empty Fruit Bunch via Dilute-Acid Hydrolysis and Fermentation by Mucor indicus andSaccharomyces cerevisiae Agricultural Journal v.6, i.2, p. 54-59, 2011

MOSIER, N.; WYMAN, C.; DALE, B.; ELANDER, R.; LEE, Y. Y.; HOLTZAPPLE, M., LADISCH, M. Features of promising technologies for pretreatment of lignocellulosic biomass. Bioresource Technology, v. 96, p. 673-686, 2005.

MORRISON, R. T.; BOYD, R. N. Química Orgânica. 8. ed. Lisboa: Fundação Calouste Gulbernkian, 1983.

NAKAMURA, Y.; SAWADA, T.; INOUE, E. Mathematical model for ethanol production from mixed sugars by Pichia stipitis. J. of Chemical Technol. And Biotechnol, v. 76, p. 586-592, 2001.

OLSSON, L.; HAHN-HÄGERDAL, B. Fermentation of lignocellulosic hydrolysates for ethanol production. Enzyme and Microbial Technology, v. 18, p. 321-331, 1996.

PANDEY, A.; SOCCOL, C. R.; NIGAM, P.; SOCCOL, V. T. Biotechnological potencial of agro-industrial residues. I: sugarcane bagasse. Bioresource Technology, v. 74, p. 69-80, 2000. 
PARAJÓ, J. C.; DOMÍNGUEZ, H.; DOMÍNGUEZ, J. M. Biotechnological production of xylitol. Part 3: Operation in culture media made from lignocellulose hydrolysates. BioresourceTechnology, v. 66, p. 25-40, 1998 b.

PASCUAL, C.; ALONSO, A.; GARCIA, I.; ROMAN, C.; KOTYK, A. Effect of ethanol on glucose transport, key glycolytic enzymes and proton extrusion in Saccharomyces cerevisiae. Biotechnology \& Bioengineering, v. 32, p. 374-378, 1988.

PELCZAR,M.;REID,R.;CHAN,E.C.S. Microbiologia . São Paulo:Mc Graw Hill, 1980, v1, 566p..

PEREIRA JR., N.; BON, E. P. S.; FERRARA, M. A. Tecnologia de bioprocessos - Séries em Biotecnologia. Rio de Janeiro: Escola de Química - UFRJ, 2008.

REES E.M.R, STEWART G.G., The effects of increased magnesium and calcium concentrations on yeast fermentation performance in high gravity worts. J I Brewing v. 103, p.287-91. 1999.

ROBERTO, I. C.; FELIPE, M. G. A.; MANCILHA, I. M.; VITOLO, M.; SATO, S.; SILVA, S. S. Xylitol production by Candida guilliermondii as an approach for the utilization of agroindustrial residues. Bioresource Technology, Essex, n.51, p.255-257, 1995.

RODRIGUES R.;LU, C.F; LIN,B.; JEFFRIES T.W .Fermentation kinetics for xilitol production by a Pichia stipitis $\mathrm{D}$-Xylulokinase mutant previously grown in spent sulfite liquor. Applied Microbiology Biotechnology v. 148: p. 199-209, 2008.

RODRIGUEZ-CHONG A., RAMIREZJ.A., GARROTE G., VAZQUEZ M. Hydrolysis of sugar cane bagasse using nitric acid: A kinetic assessment Journal of Food Engineering, v.61, n.2, p. 143-152, 2004

SAHA, B.C. Hemicellulose bioconversion. J. Ind. Microbiol. Biotechnol, v. 30, p. 279-291, 2003.

SANCHEZ, C. Lignocellulosic residues: Biodegradation and bioconversion by fungi Biotechnology Advances, v.27, n.2, mar-abr 2009, p.185-194 
SANTOS, J. C.; CONVERTI, A.; CARVALHO, W.; MUSSATTO, S. I.; SILVA, S. S. Influence of aeration rate and carrier concentration on xylitol production from sugarcane bagasse hydrolysate in immobilized-cell fluidized bed reactor. Process Biochemistry, v. 40, p. 113-118, 2005a.

SANTOS, J. C.; MUSSATTO, S. I.; DRAGONE, G.; CONVERTI, A.; SILVA, S. S. Evaluation of porous glass and zeolite as cells carriers for xylitol production from sugarcane bagasse hydrolysate. Biochemical Engineering Journal, v. 23, p. 19, 2005b.

SARROUH, B. F. ; BRANCO, R.F. ; SILVA, S.S. Biotechnological Production of Xylitol: Enhancement of Monosaccharide Production by Post-Hydrolysis of Dilute Acid Sugarcane Hydrolysate. Applied Biochemistry and Biotechnology, v. 153, p. 163-170, 2009

SARROUH, B.F.; SANTOS, D.T.; CONVERTI,A.; SILVA,S.S .Technical/economical evaluation of sugarcane bagasse for bioetanol production.Chemical Engineering and Technology,v.30(2),p.1-7.2007.

SCHLITTLER, L. A. F. S Engenharia de um Bioprocesso para Produção de Etanol de Bagaço de Cana-de-Açúcar 2006 174p. Dissertação (Mestrado em Ciências) - Universidade Federal do Rio de Janeiro - UFRJ.

SILVA, R; HARAGUCHI, S. K.; MUNIZ, E. C. and RUBIRA, A. F. Aplicações de fibras lignocelulósicas na química de polímeros e em compósitos. Quím. Nova. v.32, n.3, p. 661-671, 2009.

SILVA,S.S., VITOLO,M.PESSOAJr.,A.,FELIPE,M.G.A. Xylose reductase and xilitol dehydrogenase activities of D-xylose-xylitol-fermenting Candida guilliermondii. Journal of Basic Microbiology,v.36,1996a.

SLININGER, P. J.; BOTHAST, R. J. Optimum pH and Temperature Conditions for Xylose Fermentation by Pichia stipitis. Biotechnology and Bioengineering, $v$. 35, p. 727-731, 1990. 
SLININGER P.J., DIEN B. S.,GORSICH S. W. and LiuAPPLIED Z. L. Nitrogen source and mineral optimization enhance $d$-xylose conversion to ethanol by the yeast Pichia stipitis NRRL Y-7124. Microbiology and biotechnology.Volume 72, Number 6, 1285-1296, 2006.

SUN, J. X.; SUN, X. F.; SUN, R.C.; SU, Y.Q. Fractional extraction and structural characterization of sugarcane bagasse hemicelluloses. Carbohydrate Polymers, v. 56, p. $195-204,2004$.

SUN, Y.; CHENG, J.J. Dilute acid pretreatment of rye straw and bermudagrass for ethanol production. Bioresource Technology, v. 96, p. 1599-1606, 2005.

TEIXEIRA, L. C.; LINDEN, J. C.; SCHROEDER, H. A. Optimizing peracetic acid pretreatment conditions for improved simultaneous saccharification and cofermentation (SSCF) of sugarcane bagasse to ethanol fuel. Renewable Energy, v. 16, p. $1070-1073,1999$.

USA DEPARTMENT OF ENERGY. From biomass to cellulosic ethanol. Disponível em:< http://genomicsgtl.energy.gov/biofuels_Placemat2.pdf>. Acessado em: Nov.2009.

ZALDIVAR, J.; MARTINEZ, A.; INGRAM, L. O. Effect of alcohol compounds found in hemicellulose hydrolysate on growth and fermentation of ethanologenic Escherichia coli. Biotechnology and Bioengineering, v. 68, p. 524-530, 2000.

ZHAO,X.; WANG,L.; LIU,D. Peracetic acid pretreatment of sugarcane bagasse fou enzymatic hydrolysis:a continued work.Journal of Chemical Technology and Biotechnology,v.83,p.950-956,2008.

WILSON,D.K.; KAVANAGH,K.L.; KLIMACEK, M.; NIDETZY,B. The xylose reductase (AKR2B5) structure: homology and divergence from other aldo/keto reductase and opportunities for protein engineering. Chemical Biological Interactions, v.143/144,p.515-521,2003.

WINKELHAUSEN, E.; KUZMANOVA, S. Microbial conversion of D-xylose to xilitol. Journal of Fermentation and Bioengineering, v. 86, p. 1-14, 1998. 
WYMAN, C. E. Biomass Ethanol: Technical Progress, Opportunities, and Commercial Challenges. Annu Rev. Energy Environ, v. 24, p. 189-226, 1999 XIA Y., YU X. and TSAO G. T. Identification of required nutrient components of yeast nitrogen base for Candida shehatae ATTCC 22984 fermenting xylose to ethanol Biotechnology letters. Volume 17, Number 2, 161-166 1995. 